\title{
Shift work: health, performance and safety problems, traditional countermeasures, and innovative management strategies to reduce circadian misalignment
}

\author{
This article was published in the following Dove Press journal: \\ Nature and Science of Sleep \\ 26 September 2012 \\ Number of times this article has been viewed
}

Mark R Smith

Charmane I Eastman

Biological Rhythms Research Laboratory, Rush University Medical Center, Chicago, IL, USA
Correspondence: Charmane Eastman Biological Rhythms Research Laboratory, Behavioral Sciences Department, Rush University Medical Center, 1645 West Jackson Boulevard, Suite 425, Chicago, IL 606I2, USA

$\mathrm{Tel}+\mathrm{I} 3$ | 25634787

Fax +I 3125634900

Email ceastman@rush.edu
Abstract: There are three mechanisms that may contribute to the health, performance, and safety problems associated with night-shift work: (1) circadian misalignment between the internal circadian clock and activities such as work, sleep, and eating, (2) chronic, partial sleep deprivation, and (3) melatonin suppression by light at night. The typical countermeasures, such as caffeine, naps, and melatonin (for its sleep-promoting effect), along with education about sleep and circadian rhythms, are the components of most fatigue risk-management plans. We contend that these, while better than nothing, are not enough because they do not address the underlying cause of the problems, which is circadian misalignment. We explain how to reset (phase-shift) the circadian clock to partially align with the night-work, day-sleep schedule, and thus reduce circadian misalignment while preserving sleep and functioning on days off. This involves controlling light and dark using outdoor light exposure, sunglasses, sleep in the dark, and a little bright light during night work. We present a diagram of a sleep-and-light schedule to reduce circadian misalignment in permanent night work, or a rotation between evenings and nights, and give practical advice on how to implement this type of plan.

Keywords: circadian rhythms, night work, bright light, phase-shifting, sleep, melatonin

\section{Introduction}

This review is intended for sleep and circadian-rhythms researchers, clinicians, and students. Others, such as shift workers, human resource managers, and professionals involved in shift-work health and safety issues, could skim most of it but concentrate on the sections "How to phase-shift human circadian rhythms" and "Recommended sleep-and-light schedule to reduce the circadian misalignment of night work." We tried to make these sections stand alone to guide you to practical solutions.

\section{Health problems associated with night-shift work}

A cogent body of literature has established an association between night-shift work and diverse health problems. Relative to day workers, rotating or permanent nightshift workers have increased incidence of cardiovascular disease and its known risk factors; ${ }^{1-19}$ gastrointestinal, ${ }^{15,20-24}$ metabolic, $, 5,6,8,17,25,26$ and reproductive ${ }^{27-35}$ dysfunction; overweight and obesity; ${ }^{2,5,14,17,36-41}$ and cancer. ${ }^{42-48}$ In fact, the evidence in support of a causal link between shift work and cancer is sufficiently strong that the International Agency for Research on Cancer recently classified shift work as a "probable carcinogen." 49 Data from some of these studies suggest that working as few 
as three night shifts per month for multiple years is associated with increased disease risk. ${ }^{16,26,39,42,50}$

The mechanisms by which night-shift work contributes to these disorders are not well established, but there is accumulating evidence for at least three possible mechanisms: (1) circadian misalignment, (2) chronic partial sleep deprivation, and (3) light-induced melatonin suppression during night shifts.

Workers permanently on evening shifts get even more sleep than regular day workers. ${ }^{51}$ Evening-shift workers usually have the same sleep schedule for work days and days off, and thus have even less circadian misalignment than regular day workers who go to bed and sleep later on weekends. ${ }^{52}$ Although permanent evening-shift workers are not often studied, it appears that they do not have the health risks associated with shift work. ${ }^{45}$ Nevertheless, the evening shift is not popular because it interferes with most family and social events. ${ }^{53}$

\section{Circadian misalignment}

Circadian misalignment occurs when behaviors (eg, activity, sleeping, waking, eating, drinking, etc) are forced to occur at the wrong circadian phases relative to the internal physiological circadian rhythms. Animal models indicate that chronic shifts or inversion of the light/dark (LD) cycle, or the imposition of an LD cycle to which an animal cannot entrain, increases mortality, ${ }^{54-57}$ and the increased risk of mortality is most pronounced in older animals. ${ }^{57}$ Chronic circadian misalignment in animals may increase mortality via accelerated progression of or susceptibility to disease states. ${ }^{58-68}$ In human studies, circadian misalignment is inevitably confounded with sleep deprivation, but data support the hypothesis that even brief circadian misalignment has adverse physiological sequelae. ${ }^{69}$ There are currently no data to determine how the adverse health outcomes associated with shift work are related to the extent or duration of circadian misalignment.

\section{Sleep deprivation}

Chronic partial sleep deprivation is a well-established consequence of night-shift work. This occurs in part because sleep duration is dependent on the circadian phase at which it occurs. $^{70,71}$ The longest sleep duration and the best sleep efficiency are obtained when sleep occurs around the temperature minimum (Tmin) ${ }^{72}$ which is usually a few hours before waking. Because the circadian clocks of most nightshift workers do not align with daytime sleep, ${ }^{73-84}$ their Tmin usually remains in the nighttime (working) hours, and the duration of daytime sleep is curtailed because the circadian clock promotes wakefulness. Sleep duration when working night shifts is typically reduced by a few hours. ${ }^{51,85,86}$ Experimental sleep restriction ${ }^{87-90}$ as well as epidemiological data on habitual short sleepers ${ }^{91-109}$ indicate that short sleep duration increases risk for a number of the same diseases known to be associated with night-shift work. Recent data also suggest that several weeks of the combination of circadian misalignment and sleep restriction substantially impair normal human physiology. ${ }^{10,111}$

\section{Melatonin suppression by light at night}

A third mechanism by which night-shift work could increase disease risk is via light-induced suppression of endogenous melatonin while working night shifts. Melatonin is secreted at night, and its synthesis is suppressed in a dose-dependent manner by light; greater suppression is produced with brighter light. ${ }^{12-116}$ Because melatonin is an antioxidant and has oncostatic properties, ${ }^{117,118}$ and even normal room light ( 200-300 lux) can suppress the synthesis of endogenous melatonin, shift workers could be at increased risk of cancer because their innate cancer defenses are compromised. ${ }^{47,119}$

There have been several studies showing that glasses with orange lenses that filter out short-wavelength light (blue and some green, to which the circadian system is most sensitive) can prevent light-induced melatonin suppression at night, ${ }^{120-123}$ and may also prevent suppression of circadian clock-gene rhythms. ${ }^{123}$ This could be a way to reduce the cancer risk attributed to melatonin suppression and/or clockgene disruption, although it cannot remove the risks due to circadian misalignment and partial chronic sleep deprivation. On the other hand, bright light during the night shift could preserve melatonin secretion by helping to delay circadian rhythms so that melatonin can be secreted during day sleep in a dark bedroom.

It is often taken for granted that melatonin levels will be suppressed during night work, because the circadian rhythms of most shift workers do not shift and most of their melatonin is secreted during the night shift. However, although some studies of real shift workers do report reduced levels of melatonin, ${ }^{124-126}$ many do not. ${ }^{80,81,127-129}$ This discrepancy could be due to methodological differences between studies (eg, spot urine samples versus 24-hour urine collection), lack of statistical power to detect a modest effect size, or other factors such as light-exposure history.

We found that melatonin suppression by light at night is affected by a person's light history. ${ }^{130}$ After a week that included about 4 hours of bright light daily (using sunlight 
and light boxes) there was less melatonin suppression from light at night than after a week in dim light (dark goggles when outside). Similarly, a study that included both indoor and outdoor workers ${ }^{131}$ found less melatonin suppression from light at night if they had been exposed to more light during the prior 2 weeks. Another study ${ }^{132}$ found that light-induced melatonin suppression can be affected by light history over just the past 3 days.

Given that (1) the amount of melatonin suppressed by light at night depends on light intensity and (2) light history affects the amount of melatonin suppressed by light at night, melatonin suppression will be affected by workplace light, the weather, the photoperiod (season) and use of sunglasses. Thus, it is difficult to make predictions about the exact light level during night work that will suppress melatonin. In addition, as noted by Dumont et al, ${ }^{129}$ because normal subjects show very large individual differences in nocturnal melatonin production, ${ }^{133}$ it may be impractical to attempt to identify an absolute level of melatonin that could be considered "abnormally low." Finally, Arendt ${ }^{134}$ points out that the common adrenergic beta receptor-blocking drugs like atenolol and propranolol, which suppress melatonin, are not known to be carcinogenic.

\section{Countermeasures for alertness, performance, and safety decrements during night-shift work}

Nighttime decrements of alertness in shift workers, with concomitant performance impairment and subsequent safety hazards, are well documented and have been the subject of many previous review papers. ${ }^{78,86,135-140}$ Night work occurs when the circadian clock promotes sleep, and alertness reaches its circadian nadir. Daytime sleep duration is acutely reduced because the circadian clock promotes wakefulness. Chronic partial sleep deprivation, such as that which might occur over weeks or months in shift workers, may impair night-shift performance even when recent sleep has been sufficient, and this impairment is most pronounced during the nighttime. ${ }^{141}$

There are a number of well-studied countermeasures that can be employed in an attempt to ameliorate some of the potentially dangerous side effects of shift work. These include improving night-shift alertness with stimulants, bright light, and naps, and improving daytime sleep duration with sedatives and exogenous melatonin. These countermeasures only provide some degree of symptomatic relief, because they do not address the underlying cause of the problem, which is circadian misalignment.

\section{Stimulants}

Caffeine is one of the most widely used stimulants in the world. Data from laboratory ${ }^{142-152}$ and field ${ }^{143}$ studies indicate that caffeine improves night-shift alertness and performance. However, despite these improvements, substantial impairments persist, and are pronounced late in the night shift near the circadian nadir of alertness. Another drawback of caffeine is that it disrupts daytime recovery sleep more than nighttime sleep, ${ }^{153}$ and this sleep disruption is greater in older individuals. ${ }^{154}$ Consequently, ingesting too much caffeine or consuming it too late in a night shift could further exacerbate daytime sleep difficulty.

The stimulants modafinil and the longer-acting armodafinil have been reported to attenuate night-shift sleepiness and improve alertness and performance both in healthy subjects ${ }^{155,156}$ as well as real shift workers. ${ }^{157,158}$ However, sleepiness persists, especially late in the night shifts, about the time of the circadian nadir. For example, shift workers taking $150 \mathrm{mg}$ armodafinil before night shifts were still pathologically sleepy (sleep latencies $\leq 5$ minutes on the multiple sleep latency test) at 4:00, 6:00, and 8:00 am. ${ }^{157} \mathrm{~A}$ further drawback of these medications is that they do not improve the duration or quality of daytime sleep. Healthy subjects taking modafinil prior to four consecutive night shifts had a daily daytime total sleep time (TST) that was similar to subjects taking placebo, which never exceeded 6 hours. ${ }^{155}$ Shift workers taking modafinil had a very similar daytime TST of 5.9 hours at the conclusion of the study, while those taking armodafinil fared even worse, with an average daytime TST of only 5.4 hours and a sleep efficiency of $68 \%$. This amount of daily sleep has been shown to produce degraded neurobehavioral performance with progressive worsening over several consecutive days. ${ }^{159}$

\section{Hypnotics and phase tolerance}

Daytime sleep after night-shift work can be lengthened by the administration of sedatives or hypnotics. ${ }^{160-163}$ Despite this increase in daytime sleep, decrements in night-shift alertness and performance persist. ${ }^{160-163}$ It is a pervasive misconception that shift workers would be alert during night shifts if only they could get enough sleep during the day. However, obtaining adequate sleep during the day does not mean that night-shift alertness, performance, and safety will also be normalized. Millions of years of evolution have made us diurnal animals, programmed to be sleepy at night.

Some individuals are "phase tolerant"164 in that after working at night they have the ability to sleep reasonably well 
during the daytime despite the fact that sleep occurs at the "wrong" circadian phase. In addition to individual differences in phase tolerance, both middle-aged ${ }^{154,165}$ and older adults ${ }^{166}$ are less phase tolerant than the young. However, being phase tolerant to sleeping during the day does not make one phase tolerant to being awake at night. In fact, the opposite may be true, since young subjects kept awake at night have decreased alertness and worse performance when compared to older subjects. ${ }^{167,168}$

\section{Melatonin as a sleep promoter}

Exogenous melatonin could benefit night-shift workers via two distinct mechanisms. Melatonin is a chronobiotic that can phase-shift the circadian clock. ${ }^{169}$ Shift-work studies using melatonin for this purpose will be discussed later. Melatonin also makes people sleepy, especially at high doses and under some conditions, and thus could be used to promote daytime sleep. ${ }^{170}$ Immediate-release oral melatonin, ${ }^{171}$ sustained-release or multiple doses of oral melatonin, ${ }^{172-174}$ and daytime transdermal melatonin administration ${ }^{175}$ after a night shift have been reported to modestly increase sleep quantity and quality. This improvement is most pronounced late in the daytime sleep episode ${ }^{172,175}$ and in subjects that would otherwise have poorer daytime sleep quality ${ }^{172}$ (eg, in subjects that are less phase tolerant). Results from several other studies are qualitatively similar, but did not reach statistical significance. ${ }^{176-178}$

\section{Naps}

Naps prior to or during night shifts have been shown to reduce night-shift sleepiness while improving alertness and performance. ${ }^{144,150,179-185}$ Despite this improvement, napping does not overcome the decrement in alertness that remains most pronounced at the circadian nadir. ${ }^{144,150,180-185}$ A study of unusually long naps ( 2 hours) during the night shift (1:00-3:00 or 3:00-5:00 am) made rapidly rotating factory workers slightly less sleepy at the end of the night shift and for a few hours after the end of work, but they were still very sleepy compared to ratings taken in the afternoon/ evening after their daytime sleep episodes. ${ }^{186}$ There may not be an opportunity to nap so long, or at all, during a night shift due to the nature of the work itself (eg, too busy or stressful) or the work environment (eg, no comfortable and quiet place to nap). ${ }^{187}$

In addition, napping during night shifts may be a concern because sleep inertia, the grogginess often felt upon awakening from sleep, is most severe at night. ${ }^{188,189}$ Studies of real shift workers on the job as well as in the laboratory have also shown that performance during a night shift is worse shortly after a nap compared to continued night-shift wakefulness. ${ }^{179,180}$ Therefore, time for recovery from sleep inertia after a nap (eg, 15-30 minutes) has to be built into the time taken away from work. Waking an individual (eg, resident physician or nurse) from a nighttime nap and expecting quickly made important decisions is a good recipe for a poor decision.

\section{Bright light as a stimulant}

A number of laboratory and field studies have shown that light exposure at night attenuates subjective and objective indices of sleepiness, while improving alertness and performance. ${ }^{146,152,190-202}$ Most of these studies used bright light of greater than 1000 lux, but the alerting effects of light may be present at room light levels of only 100-200 lux in subjects that have been adapted to dim light. ${ }^{200}$ The alerting effects of light are more pronounced with blue light than longer-wavelength light. ${ }^{203-205}$ Although light exposure can acutely improve alertness at night, the trough of alertness at the circadian nadir is typically still present. ${ }^{190,199}$ The acute alerting effects of light are extinguished soon after light exposure ends. ${ }^{192,200}$ The alerting effects of light at night are not likely due to suppression of endogenous melatonin, because bright light augments alertness during the daytime, when circulating levels of melatonin are low and not altered by light exposure. ${ }^{196,206,207}$

\section{Summary of countermeasures}

Combinations of countermeasures, including bright light and caffeine, ${ }^{146,152}$ as well as evening naps and caffeine, ${ }^{143,208}$ are generally more effective than an individual countermeasure for improving night-shift alertness. These countermeasures, along with education about sleep hygiene, circadian rhythms, and the importance of making sleep a high priority, are the basis of most fatigue-management plans, but they do not address the cause of the problem (ie, circadian misalignment). Although night-shift alertness can be improved to some extent by stimulants, this does not address chronic partial sleep deprivation or the impact of circadian misalignment. Likewise, daytime sleep duration can be moderately improved with sedatives and exogenous melatonin, but this does not improve night-shift alertness or attenuate circadian misalignment. Consequently, these countermeasures are most suitable for workers on rapidly rotating night-shift systems, or those working few and 
isolated night shifts, for whom phase-shifting the circadian clock is neither desirable nor achievable.

\section{Phase-shifting the circadian clock for adaptation to night-shift work How to phase-shift human circadian rhythms}

The most reliable way to reduce the sleepiness, fatigue, impaired performance, safety problems, and, presumably, health risks of shift work is to reduce circadian misalignment. We have proposed the goal of phase-shifting (resetting) the circadian clock so that the sleepiest time of day, which usually occurs during nocturnal sleep and is conveniently marked by the temperature minimum (Tmin), delays at least as far to move out of the night shift and into the daytime sleep episode. ${ }^{209}$ The Tmin typically occurs $2-3$ hours before the end of sleep under normal, entrained conditions, but at the beginning of sleep when subjects free-run. ${ }^{70,210}$ Therefore, it appears that normal sleep quality and quantity can be obtained when the Tmin falls within this range, from the beginning of sleep to about 2 hours before the end of sleep.

In order to phase-shift the circadian clock, and therefore all the circadian rhythms (including the circadian rhythms of sleepiness, performance, temperature, and melatonin), we use two basic principles. One is that when the LD cycle is shifted, circadian rhythms gradually shift to realign or reentrain to the new LD cycle. ${ }^{211}$ To phase-shift the circadian clock, it is important to create a strong shifted 24-hour LD cycle. This can be done by scheduling sleep in a very dark bedroom. The other principle is that the circadian clock can be shifted by pulses of light or by melatonin according to phase-response curves (PRCs). Thus, we can apply bright light and melatonin to enhance the phase shift produced by shifting the LD cycle using PRCs as guides for the optimal timing. For figures showing superimposed light and melatonin PRCs, see Revell and Eastman ${ }^{212,213}$ and Eastman and Burgess. $^{214}$

When shift workers choose to sleep before night work in the late afternoon and evening, their dark period is earlier than usual (advanced relative to the habitual sleep episode), creating an advanced LD cycle, which should reset the circadian clock earlier. When they choose to go to bed in the morning after night work, the dark period is later than usual, delayed, creating a delayed LD cycle, which should reset the circadian clock later. However, the circadian rhythms of real night-shift workers rarely shift to align with their new sleep schedules. One reason is that they do not maintain a consistently shifted LD cycle long enough. They are either rotated to a different shift and have to change their time of sleep or sleep at conventional times on days off. Most nightshift workers prefer to sleep after work in the morning and daytime hours, leaving the evening hours free for leisure activities with family and friends. ${ }^{53} \mathrm{~A}$ few prefer to have the mornings free (eg, for farming or child care), and to sleep in the afternoon and evening before work. Many shift workers sleep at random times, napping and grabbing whatever sleep they can. This of course does not create the consistently shifted LD cycle necessary for phase-shifting the clock and reducing circadian misalignment.

Light PRCs show that light exposure in the evening and early night before about the time of the Tmin delays the circadian clock (ie, shifts it to a later time), while exposure late in the night and morning after the Tmin advances the circadian clock (shifts it earlier).

\section{Controlling light and dark to reduce circadian misalignment}

The circadian rhythms of shift workers who go to bed after night work do not usually delay to align with sleep because they are usually exposed to bright outdoor light on the way home from work, which "hits" the phase-advance portion of the light PRC. This outdoor light is a powerful phase shifter, because it is much more intense than indoor light, even on a cloudy day. Long ago, we proposed that shift workers wear dark sunglasses to attenuate outdoor light when it would oppose the desired phase shift. ${ }^{215}$ In a simulated night-shift study we showed that wearing very dark sunglasses on the way home from the night shift can attenuate phase-advancing morning light and permit circadian rhythms to delay. ${ }^{216}$

In another simulated night-shift study, ${ }^{217}$ we tested 9-hour delays of the sleep (dark) episodes, which put sleep after night work, and 9-hour advances, which put sleep before night work. We used bright light exposure (3 hours of $\sim 5000$ lux), timed to facilitate or impede the phase shift by putting the light on the "right" or "wrong" portion of the PRC. For example, when sleep was advanced, facilitating bright light at the "right" time was timed to phase-advance the circadian clock, while conflicting bright light at the "wrong" was timed to phase-delay the circadian clock. With facilitating bright light, almost all of the subjects had their Tmin shift to within their sleep episodes. For the groups that were exposed to conflicting bright light, very few had Tmin that shifted 
that far. This study showed how bright light can inhibit the desired phase shift when it consistently hits the wrong part of the PRC.

In a subsequent simulated night-shift study, ${ }^{218}$ we used facilitating light (3-hour exposures) during night shifts to promote delays and align the circadian clock with daytime sleep. We tested three light intensities: high ( $~ 5700$ lux), medium ( $\sim 230$ lux) and low (<250 lux). Subjects wore sunglasses on the way home and followed a regular daytime sleep schedule in very dark bedrooms. There was no significant difference between the groups who received high- and medium-intensity light; $100 \%$ of the subjects in the highintensity group and $85 \%$ of those in the medium-intensity group delayed their Tmin into daytime sleep. In contrast, only $42 \%$ of those in the low-intensity group delayed that far. Therefore, very bright light was not necessary to reduce circadian misalignment significantly.

Boivin and James ${ }^{219}$ set up light boxes in nursing stations and turned them on during the first 6 hours of 8-hour night shifts. Permanent night nurses were asked to spend as much time near the light boxes as their workload permitted, and were intermittently exposed to $\sim 2000$ lux. They wore sunglasses during the morning commute home, and had a fixed 8-hour daytime sleep schedule. The Tmin delayed to within the daytime sleep period for seven of the nine subjects; it delayed slightly too far for the other two subjects. Control subjects had to adhere to the same 8-hour daytime sleep schedule, but they were not exposed to the light boxes and did not wear sunglasses. Only three of the eight control subjects got their Tmin into day sleep. This study showed that (1) bright light can be used in a real shift-work situation and (2) adhering to a regular daytime sleep schedule was not enough for most subjects; bright light during the night shift and/or sunglasses for the commute home was necessary to ensure that their circadian clock delayed far enough.

\section{Phase markers of the circadian clock}

For many years, the circadian rhythm of body temperature, especially the lowest temperature each day - the Tmin was the gold-standard marker used to infer the time of the circadian clock. More recently, the circadian rhythm of endogenous melatonin, especially the nocturnal rise - the dim-light melatonin onset (DLMO) - has become the preferred phase marker because of its reliability and ease of measurement from saliva samples. ${ }^{220,221}$ The DLMO usually occurs about 2-3 hours before bedtime 222 and 6-8 hours before the Tmin. ${ }^{200,223-230}$ In our lab, we routinely measure the DLMO and add 7 hours to estimate the time of the Tmin, because it is useful to visualize the phase position of the Tmin (the sleepiest time of day and an approximation for the crossover point on the light PRC).

\section{Using melatonin to reduce circadian misalignment}

The melatonin PRCs for 0.5- and 3.0-mg doses show that taking melatonin in the afternoon/evening, about 5-7 hours before natural fall-asleep time, can help phase-advance circadian rhythms, while taking melatonin at the end of the sleep episode and for a few hours after waking can help phase-delay rhythms. The optimal times depend on the dose. ${ }^{231}$ For shift workers who want to go to bed in the morning after night work, and therefore need to phase-delay their circadian clocks, melatonin should be taken in the morning before daytime sleep. If they want to go to sleep before night work, and therefore need to phase-advance their circadian clocks, then melatonin should be taken in the afternoon/ evening before sleep.

We conducted a simulated night-shift study to test the phase-advancing and sleep-promoting effects of melatonin. ${ }^{232}$ Subjects went to bed in the afternoon, before the night shifts, which was 7 hours before their usual baseline bedtime. They took melatonin or placebo before bed, which fell within the phase-advance portion of the melatonin PRCs. After 8 days with melatonin taken for the first 4 days, the DLMO advanced $\sim 4$ hours with $3.0 \mathrm{mg}$ melatonin, $\sim 3$ hours with $0.5 \mathrm{mg}$ melatonin and $<2$ hours with placebo. Thus, melatonin enhanced the phase shift produced by the advance of the LD cycle, but the circadian rhythms of many subjects did not advance enough to get their Tmin within sleep. Melatonin had a sleep-promoting effect and was able to keep sleep duration equivalent to baseline for the 4 days of administration. Since advancing human circadian rhythms is more difficult than delaying them, ${ }^{209,217}$ it is possible that a similar study with a delayed sleep schedule and melatonin in the morning before daytime sleep would have produced more circadian alignment.

Melatonin was tested on nurses and hospital personnel who worked seven consecutive 10-hour night shifts alternating with 7 days off. ${ }^{233}$ During one 14-day block, they took $0.5 \mathrm{mg}$ melatonin every day at bedtime, and during another they took placebo (double-blind crossover). Seven consecutive night shifts are unusual, and we might expect that the circadian rhythms of many subjects would shift substantially after that time, even on placebo. However, in this field study with uncontrolled sleep schedules and uncontrolled light and 
dark, most of these night workers did not phase-shift very much, even with melatonin.

\section{Combinations of bright light and melatonin to reduce circadian misalignment}

We designed a simulated night-shift study to assess the relative importance of different interventions that could promote phase delays during five consecutive night shifts (11:00 pm to 7:00 am). ${ }^{234}$ The interventions were: (1) intermittent bright-light pulses during night shifts in the lab ( $\sim 5000$ lux, 20 minutes/hour, 4-5 pulses/night); (2) extremely dark ( $2 \%$ light transmission) or normal (15\% transmission) sunglasses worn outside during daylight with the purpose of attenuating advancing morning light during the commute home (subjects were run in three summers in Chicago); (3) a strict, regular 7 hours for daytime sleep at home (8:30 am to $3: 30 \mathrm{pm}$ ) in bedrooms that we made "darkroom dark"; and (4) melatonin (1.8 $\mathrm{mg}$ sustained release) ingested in the morning prior to daytime sleep (both for its phase-delaying and sleep-promoting effects). We used intermittent bright light, as in one of our previous studies, ${ }^{235}$ because it is a more efficient light stimulus for phase-shifting the human circadian clock than continuous bright light, ${ }^{236-238}$ and because it is more practical for workers to receive in the workplace.

Subjects were free to sleep whenever they wanted during a baseline week, because we wanted them to start the night shifts with a range of baseline phase positions as would occur in real shift workers. The baseline Tmin (DLMO + 7 hours) ranged from about 3:00 to 10:00 am, and was the most important factor that determined whether subjects' circadian clocks shifted to align with the day-sleep schedule. We divided subjects into those whose baseline Tmin was earlier than 7:00 am, and therefore fell within the time for night work, and those whose Tmin was later (see Figure 4 in Revell and Eastman ${ }^{213}$ ). Bright outdoor light when traveling home from the night shift likely fell on the phase-advance portion of the light PRCs of the "earlier" subjects, whereas for the "later" subjects the same outdoor light occurring at an earlier circadian time was likely phase-delaying.

The circadian clocks of all of the "later" subjects $(n=23)$ became completely aligned with the day-sleep schedule, such that their Tmin after five night shifts occurred within the day-sleep episodes, even with minimal interventions (normal room light during night shifts $[\sim 150$ lux], normal sunglasses [15\%], and fixed daytime sleep [dark] episodes). In contrast, of the "earlier" subjects $(n=42)$ only $30 \%$ got their Tmin into day sleep with the same minimal interven- tions. All the subjects in the group given melatonin and extremely dark sunglasses $(\mathrm{n}=13)$, including many "earlier" subjects got their Tmin into day sleep. We don't know if melatonin would have worked as well combined with normal sunglasses, because that combination was not tested. As long as the combination included bright light during the night shifts $(n=26)$, all but one of the subjects delayed their Tmin into sleep; they did not need melatonin or extremely dark sunglasses.

This study showed that (1) complete realignment complete reentrainment - of circadian rhythms to a daytime sleep schedule was possible after five night shifts, (2) bright light during the night shift was not necessary as long as subjects started out with relatively later circadian phases, wore sunglasses on the way home from the night shift, and maintained a regular daytime sleep schedule, (3) melatonin helped delay circadian rhythms as long as bright light was drastically attenuated, and (4) bright light during the night shifts was the most reliable way to ensure complete realignment of circadian rhythms with daytime sleep.

Importantly, when we compared subjects with partial realignment (Tmin into the first half of daytime sleep) to subjects with complete realignment (Tmin into the second half of daytime sleep) their sleepiness and performance during night shifts were similar to each other, and both were significantly better than for the subjects whose Tmin did not reach daytime sleep. Thus, complete realignment was not necessary to substantially improve night-shift alertness and performance. $^{239}$

\section{Creating partial circadian alignment to accommodate days off}

The simulated night-shift study discussed above ${ }^{234,239}$ showed we could reliably produce complete circadian alignment to night work and day sleep using only a total of 80-100 minutes of intermittent bright light per night shift. But if the circadian rhythms of real night workers delayed this far, then they would suffer from circadian misalignment on days off; they would have trouble sleeping at night and being alert during the day. We also showed that partial alignment to daytime sleep and night work was sufficient for improving night-shift alertness and performance. So in order to accommodate days off, we designed a sleep-and-light schedule to produce a compromise between complete alignment with a daytime sleep schedule and complete alignment with a normal nocturnal sleep schedule. We conducted a series of studies to test this schedule. ${ }^{240-243}$

We wanted to study only "earlier" people, because they have the most trouble adapting to night work, so we put 
subjects on an 11:00 pm to 7:00 am baseline sleep schedule for 3 weeks, with weekend bed and wake times allowed to be up to 1 hour later. Subjects were required to receive at least 15 minutes of outdoor light between 8:00 and 9:00 am. Thus, they began the study with a sleep schedule and morning light exposure typical of most day workers, and they all had "earlier" baseline phases (Tmin before 7:00 am) when the night shifts started, as shown in Figure 1 of Smith et al. ${ }^{244}$

Figure 1 shows that after the 3 weeks of baseline, represented by the blue sleep rectangle on day 1 , there were three night shifts, 2 days off, five more night shifts, and 2 days off. Experimental and control subjects had the same sequence of night shifts and days off, but experimental subjects were exposed to intermittent delaying bright light during the night shift, 15-minute light pulses ( 4000 lux) separated by 45 minutes in room light ( $<50$ lux), whereas control subjects remained in room light.

Experimental subjects followed the sleep schedule shown by the blue rectangles in Figure 1, whereas control subjects were allowed to sleep whenever they chose after night shifts and on days off. Experimental subjects had to remain in bed in the dark for 7 hours after the night shifts (8:30 am to $3: 30 \mathrm{pm})$ except following the last night shift in a series, when time in bed was 5 hours (8:30 am to 1:30 pm). The shorter sleep episodes before days off were designed to build up a small amount of homeostatic sleep pressure - a little sleep deprivation - to help subjects fall asleep earlier on the subsequent days off. Sleep on days off was from 3:00 am to noon.

Our goal was to delay the circadian clocks of experimental subjects so that the Tmin occurred during the hours that daytime sleep and days off sleep overlapped, so it would be in the beginning of sleep after night work and near the end of sleep on days off.

We conducted these studies in the summers, when conflicting, phase-advancing, bright light on the way home would be a powerful force to overcome. Experimental subjects wore Uvex (Smithfield, RI) sunglasses with Bandit frames and Espresso lenses (15\% visual light transmission, increasing from $0 \%$ at $400 \mathrm{~nm}$ to about $22 \%$ at $650 \mathrm{~nm}$ ). Control subjects wore the same frames with lighter lenses (36\% light

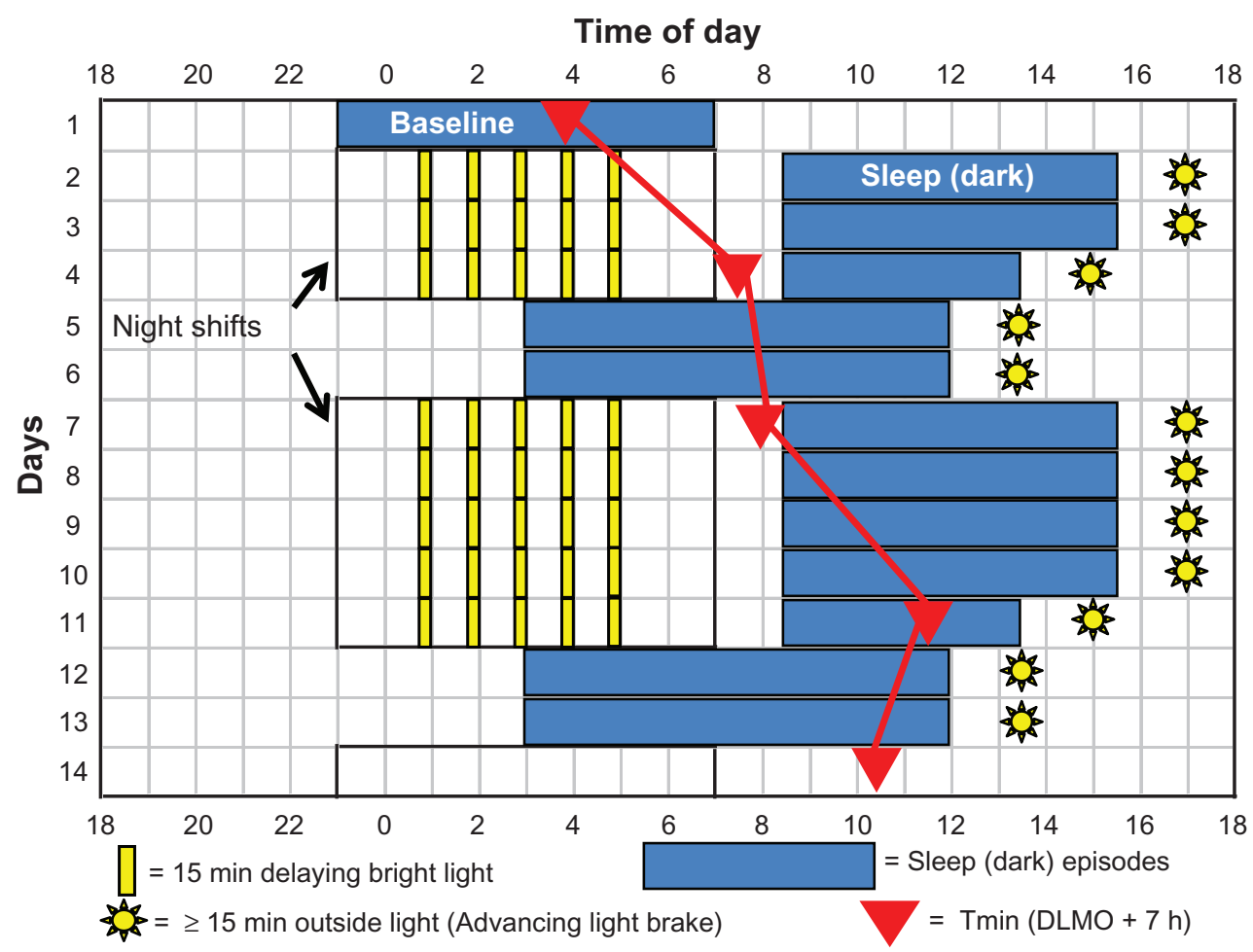

Figure I Sleep-and-light schedule for night-shift work that we tested to determine if it could align circadian rhythms with the sleep schedule enough to move the temperature minimum (Tmin) to within sleep.

Notes: Blue rectangles represent scheduled sleep times for experimental subjects. They slept at home, in bedrooms that we made completely dark, and "worked" their night shifts in the lab. They were exposed to intermittent bright light ( 4000 lux) during the night shifts (yellow rectangles), timed to delay their circadian rhythms. They wore sunglasses $(\sim 15 \%$ visual light transmission) to reduce the intensity of phase-advancing daylight when traveling home from the night shift. They were required to go outside within 2 hours after wake time (yellow sun symbols) to get phase-advancing light, the "light brake," to keep their circadian clocks from delaying too far. The filled red triangles represent the Tmin from four different studies, ${ }^{240-243}$ and show how the circadian clock shifted during the sequence of night shifts and days off. The Tmin reached the target zone (falling within sleep both after night work and on days off) after about a week on the schedule.

Abbreviation: DLMO, dim-light melatonin onset. 
transmission, increasing from $0 \%$ at $400 \mathrm{~nm}$ to about $55 \%$ at $650 \mathrm{~nm}$ ). Both spectral transmission curves are in Lee et al, ${ }^{240}$ and can be seen at http://www.uvex.com. All subjects wore their sunglasses whenever outside during daylight. The purpose of the sunglasses was to attenuate phase-advancing bright light after night work, but we instructed subjects always to wear them when outside during daylight because we wanted to make it a habit.

Experimental subjects were required to go outside for 15 minutes of afternoon light exposure within 2 hours of their scheduled wake times (yellow suns in Figure 1). This advancing light exposure, the "light brake," was intended to stop their circadian clocks from delaying too far. We wanted to avoid what happened in one of our previous studies, ${ }^{218}$ when many subjects whose Tmin had delayed to daytime sleep continued to delay around the clock when they were abruptly placed back on their normal nocturnal sleep schedule.

Four separate studies were run, each with an experimental and control group progressing further through the schedule shown in Figure 1. Each new study began with the 3-week baseline and ended with the final phase assessment on a later day in the sequence (a day marked by a red triangle). Thus, we acquired "snapshots" of the circadian phase that subjects obtained as they progressed through the schedule. The filled red triangle on day 1 illustrates the average Tmin determined after 2 weeks of baseline for all the subjects in the four experimental groups $(n=41)$. The triangle on day 4 shows the average final Tmin \pm standard deviation for study 1 (7:36 \pm 1.4 hours, $\mathrm{n}=11),{ }^{240}$ day 7 for study $2(7: 59 \pm 1.2$ hours, $\mathrm{n}=9),{ }^{241}$ day 11 for study $3(11: 34 \pm 1.6$ hours, $\mathrm{n}=12),{ }^{242}$ and day 14 for study $4(10: 22 \pm 2.0$ hours, $n=9) .{ }^{243}$

The red lines connecting the red Tmin triangles in Figure 1 are for illustrative purposes, and do not necessarily represent exactly how the circadian clocks shifted, which may not have been linear. Nonetheless, we can surmise that the Tmin reached the target zone (falling within sleep both after night work and on days off) by day 8 or 9 in Figure 1, after 7 or 8 days on the sleep and light schedule. Because the final Tmin of the experimental group in study 3 (that ended on day 11) was later than necessary, we did not include the last light pulse from 4:45 to 5:00 am in study 4. Therefore, experimental subjects in study 4 followed the entire schedule with four rather than five light pulses, a total of only 1 hour of bright light per night shift, and still ended up with their Tmin in the target zone.

Around the time that these studies started, exciting discoveries showed that the human circadian system was most sensitive to blue light. ${ }^{245-248}$ To test whether the phase delays could be augmented by using lamps emitting additional blue light, we studied an additional group of subjects in study 1, which had two night shifts and then the final phase assessment. They received an identical number and pattern of intermittent light pulses, but were exposed to blue-enriched polychromatic light from fluorescent fixtures $(17,000 \mathrm{~K}, \sim 3900$ lux) rather than from "white" polychromatic fluorescent fixtures $(5095 \mathrm{~K}, \sim 4000$ lux $) .{ }^{249}$ The final Tmin for the blue-enriched group was not later than the white-light group $(7: 18 \pm 1.3$ hours vs $7: 36 \pm 1.4$ hours $){ }^{249}$ We believe that the exact pattern, duration, and wavelength of light during the night shifts may not be crucial for practical purposes. The circadian clock will eventually delay, as long as the delayed sleep schedule is maintained and sunglasses are worn on the way home. If the rhythms delay too far, then the afternoon light brake should stop them.

On average, the circadian rhythms of the control subjects did not shift very much. Their Tmin stayed within the night shift or during the time of the commute home. The final Tmin of the control subjects in studies $1-4$ were $4: 48 \pm 1.3$ hours, 5:00 \pm 1.8 hours, 7:39 \pm 2.9 hours, and 6:24 \pm 3.8 hours, respectively. However, there were large individual differences among the control subjects, which depended on the sleep times (and thus times of light exposure) that they self-selected. Figure 2 shows a control subject who adopted a sleep schedule that was similar to what we required of the experimental group; she went to bed relatively soon after the night shifts and slept until the afternoon, and went to bed and woke up late on days off. Her final Tmin fell within the target zone. In contrast, Figure 3 illustrates the sleep schedule of a control subject whose sleep pattern was similar to that of many nightshift workers. He went to bed and woke up relatively early on days off, often stayed awake during the morning hours after night shifts, and occasionally napped in the evening before the night shifts. Thus, he did not maintain a consistently delayed or advanced sleep (dark) period. His Tmin did not shift out of the night-shift hours, and he had the circadian misalignment typical of most night-shift workers.

We previously reported that subjects who had either partial or complete realignment to a night-work and daysleep schedule had improved night-shift alertness and performance compared to subjects whose rhythms did not shift. ${ }^{239}$ However, we did not have measures during day work to judge the extent of this night-shift improvement. In the series of studies shown in Figure 1, subjects completed computerized test batteries lasting $\sim 25$ minutes four times during their daytime baseline at 10:05 am, 12:05 pm, 2:05 pm, and 4:05 pm, and four times during the night shifts at 12:05, 2:05, 


\section{Time of day}

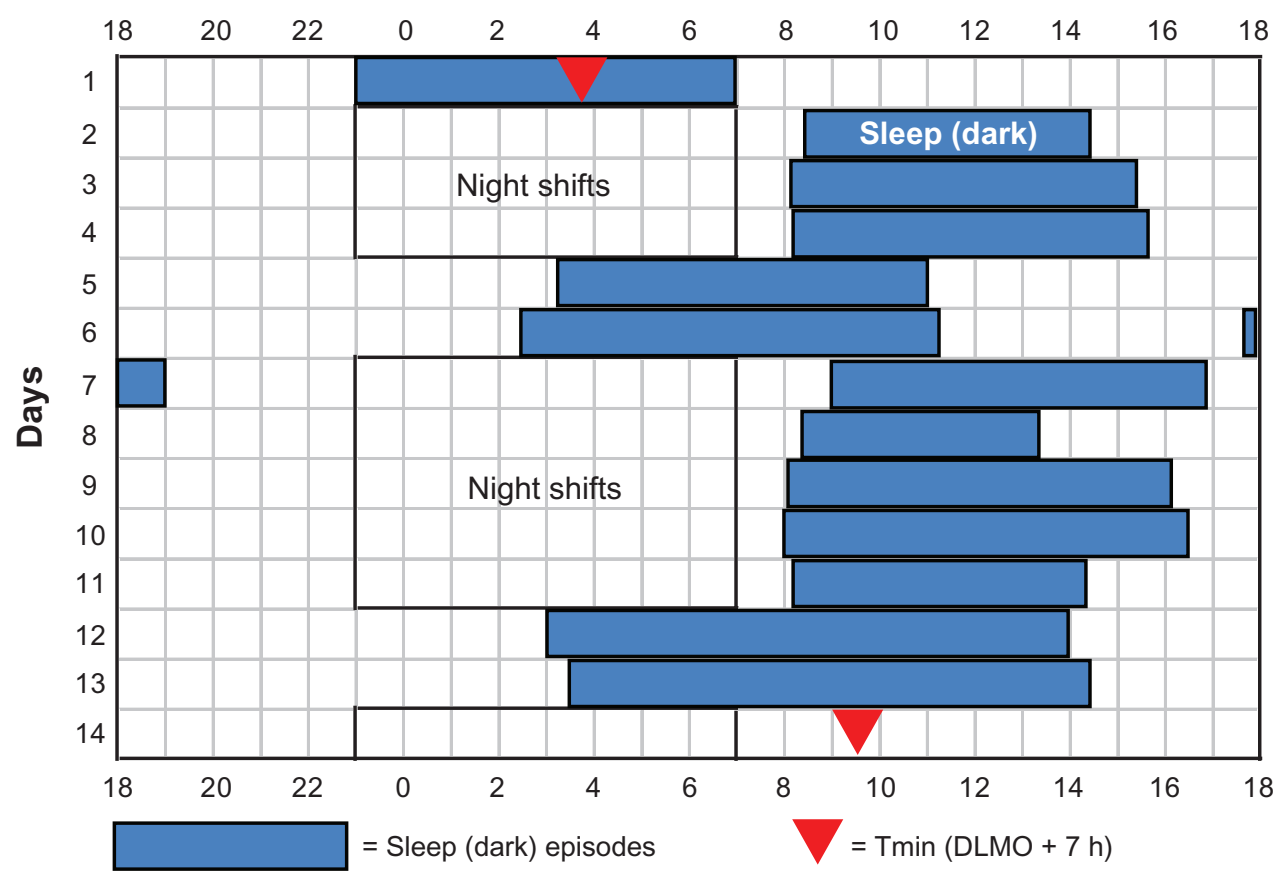

Figure 2 Sleep times (blue rectangles) and baseline and final temperature minima (Tmin, filled red triangles) for a control subject in study 4.

Notes: Control subjects remained in normal room light during night shifts ( $<50$ lux), wore light sunglasses $(\sim 36 \%$ transmission) when outside during daylight hours, and self-selected their sleep times (from day 2 on). This subject followed a sleep schedule similar to what was required of the experimental subjects. The Tmin for this subject (red triangle on day 14) eventually fell within the times she chose to sleep. Thus she ended up with very little circadian misalignment.

Smith MR, Fogg LF, Eastman Cl. Practical interventions to promote circadian adaptation to permanent night shift work: study 4. J Biol Rhythms. 2009;24:I6I-I72, Copyright (C) 2009 by the Journal of Biological Rhythms. Reprinted by Permission of SAGE Publications. ${ }^{243}$

Abbreviation: DLMO, dim-light melatonin onset.

4:05, and 6:05 am. Each test bout included several measures of fatigue, mood, and objective performance. Subjects in studies 3 and 4 were classified as not realigned (not reentrained) if their final Tmin was earlier than 8:30 am, putting it within the time corresponding to the night shift or during the travel home time, partially realigned if their final Tmin fell within the first half of the daytime sleep, between 8:30 am and noon, and completely realigned if their final Tmin fell within the second half of daytime sleep, after noon. ${ }^{244}$

Figures 4 and 5 show performance data, with average daytime scores depicted as horizontal dotted lines, and higher values on the $y$-axis depicting poorer performance. An example of how performance changed as the time of night progressed is shown with procedural reaction time (Figure 4). The green filled circles show the typical pattern for shift workers whose circadian rhythms are not aligned with night work and day sleep: a steady slowing of reaction time as the night shift progressed. In contrast, performance of the partially and completely realigned groups was (1) significantly better than the not realigned group, (2) similar to each other, and (3) close to their daytime baseline level. To illustrate how performance changed across successive night shifts, Figure 5 shows simple reaction time. During the first night shift, as expected, all subjects had poorer performance (more lapses) than during the day shifts. The group that was not realigned (those with the most circadian misalignment) continued to have a large number of lapses during subsequent night shifts, whereas the partially and completely realigned groups improved across successive night shifts. There was a slight (but not statistically significant) difference between the partially and completely realigned groups, and by the end of the series of night shifts both groups were close to their daytime level of lapses. On all of the other tests of alertness, mood, and performance, the partially and completely realigned groups were more similar, as in Figure 4. The simple reaction-time test is similar to the psychomotor vigilance task (PVT), ${ }^{250}$ and is known to be very sensitive to sleep loss and circadian misalignment. On the other hand, the procedural reaction-time test required decision-making in addition to speed.

The degree of improvement produced by our sleep and light schedule, with performance close to daytime levels and sustained over consecutive night shifts, is not obtained with conventional countermeasures that do not phase-shift circadian rhythms. Our subjects were young, mostly in their 20 s, so it is important to test our sleep-and-light schedule on middle-aged and older adults, who may be less phase tolerant 


\section{Time of day}

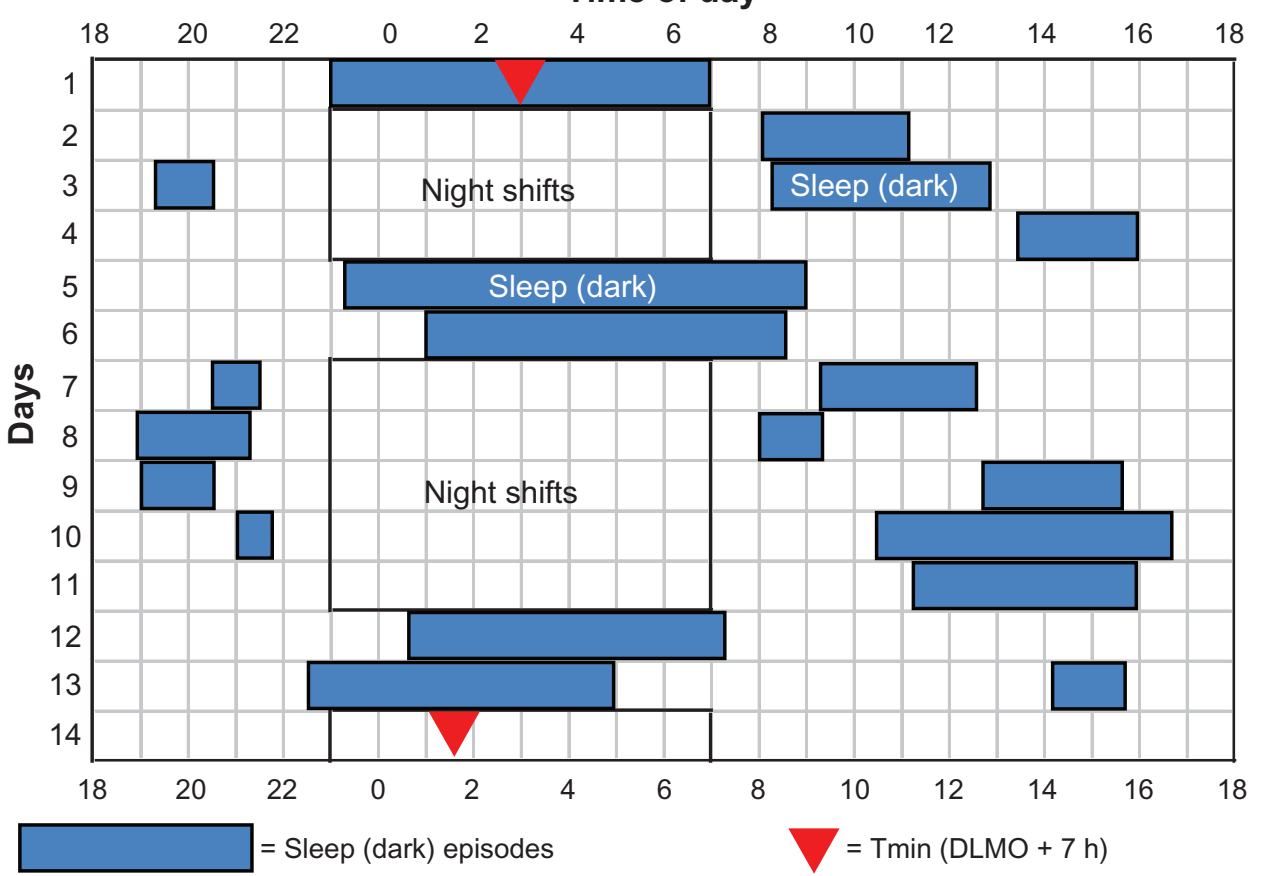

Figure 3 Sleep times for a control subject in study $4^{243}$ that had short daytime sleep after night shifts, sometimes stayed awake for many hours in the morning after night work, napped before some night shifts, and went to sleep and woke up relatively early on days off.

Smith MR, Fogg LF, Eastman Cl. Practical interventions to promote circadian adaptation to permanent night shift work: study 4. J Biol Rhythms. 2009;24:I6I-I72, Copyright (C) 2009 by the Journal of Biological Rhythms. Reprinted by Permission of SAGE Publications. ${ }^{243}$

Notes: Control subjects did not receive bright light during the night shifts and wore light sunglasses ( $36 \%$ transmission) when outside. The temperature minimum (Tmin) of this subject did not shift out of the time for night work. Thus, he continued to have circadian misalignment.

Abbreviation: DLMO, dim-light melatonin onset.

for obtaining daytime sleep with only partial circadian realignment. ${ }^{165,251}$ However, as mentioned earlier, older people are more phase tolerant for working at night; they have less severe decrements in response to sleep deprivation and circadian misalignment. ${ }^{167,168}$

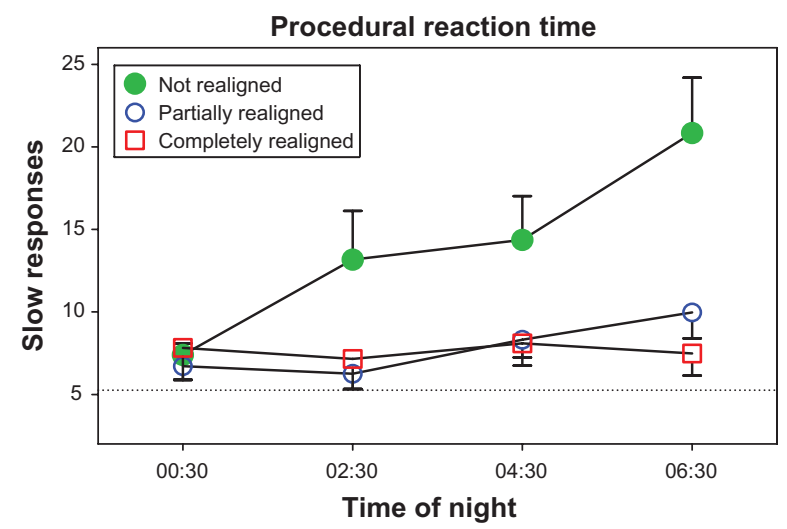

Figure 4 The number of slow responses on the procedural reaction-time task averaged over three night shifts (days 8-10 in Figure I) for subjects whose circadian clocks were not realigned $(n=12)$, partially realigned $(n=21)$, or completely realigned $(n=6)$ to night work by the end of their series of night shifts and days off.

Notes: The dashed horizontal line shows the average values for all subjects during baseline day shifts. Error bars show the standard error of the mean. The performance of the subjects who were partially or completely realigned was very good compared to the subjects who had the most circadian misalignment.

Copyright (c) 2009. Smith MR, Fogg LF, Eastman Cl. A compromise circadian phase position for permanent night work improves mood, fatigue, and performance. Sleep. 2009;32: $148 \mid-1489 .^{244}$
We have shown that our sleep-and-light schedule produced partial realignment of circadian rhythms with daytime sleep, so that the Tmin, the sleepiest time of day, occurred within sleep. Furthermore, our experimental subjects were able to follow the prescribed sleep schedule, sleeping for

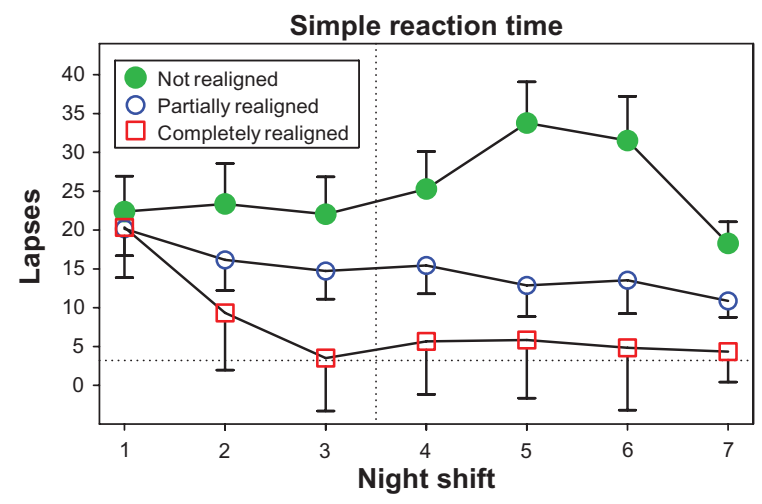

Figure 5 The number of lapses (reaction time $>500$ milliseconds) at 6:30 am on the simple reaction-time task across successive night shifts for subjects whose circadian clocks were not realigned $(n=12)$, partially realigned $(n=21)$, or completely realigned $(n=6)$ to night work by the end of their series of night shifts and days off.

Notes: The dashed vertical line indicates that 2 days off occurred between night shifts 3 and 4 . The dashed horizontal line shows the average values for all subjects during baseline day shifts. Error bars show the standard error of the mean. The performance of the subjects who were partially or completely aligned was greatly improved compared to those who had the most circadian misalignment.

Copyright (C) 2009. Smith MR, Fogg LF, Eastman Cl. A compromise circadian phase position for permanent night work improves mood, fatigue, and performance. Sleep. 2009;32: | 48|-| $489 .{ }^{244}$ 
nearly all of the allotted time in bed, both during daytime sleep and on days off. ${ }^{242,243}$ Finally, performance during the night shift was substantially improved, and was close to or at daytime levels. Given the success of our procedure, we think it is time to test it in real shift workers.

\section{Recommended sleep-and-light schedule to reduce the circadian misalignment of night work}

Figure 6 shows a sleep-and-light schedule that could be used to produce partial circadian alignment in permanent nightshift workers. The same type of schedule could be used for 12-hour shifts, except that the night shifts would start 4 hours earlier. This schedule (Figure 6) differs from the schedule we tested (Figure 1) in minor ways in order to make the procedure easier to understand and more practical for real shift workers. Figure 6 shows a sequence with blocks of five night shifts (11:00 pm to 7:00 am) alternating with 2 days off. The workers should be exposed to as much bright light as possible during their night shifts, especially between midnight and 4:00 am. We believe that the goal of having the sleepiest time of day - the temperature minimum (Tmin) - occur within sleep both after night work and on days off will eventually be reached regardless of the exact sequence of night shifts and days off. There will be a balance of forces that make the circadian clock later (phase-delaying bright light during the night shifts and the "pull" of the delayed sleep [dark] episodes) and forces that make the clock earlier (advancing light brake). Once this goal is reached, circadian phase should remain relatively stable for weeks or months until there is a vacation that changes the sleep schedule.

Figure 6 shows the expected path of the circadian clock (marked by the Tmin, red triangles) for a worker who starts the schedule after working days and thus has an early Tmin of 4:00 am. Most individuals who haven't worked days or morning shifts will start out with Tmin that are later than 4:00 am, and will reach the target zone sooner. Based on our simulated night-shift studies, ${ }^{234,240-243}$ we expect that the

\section{Sleep and light schedule to reduce circadian misalignment in night workers}

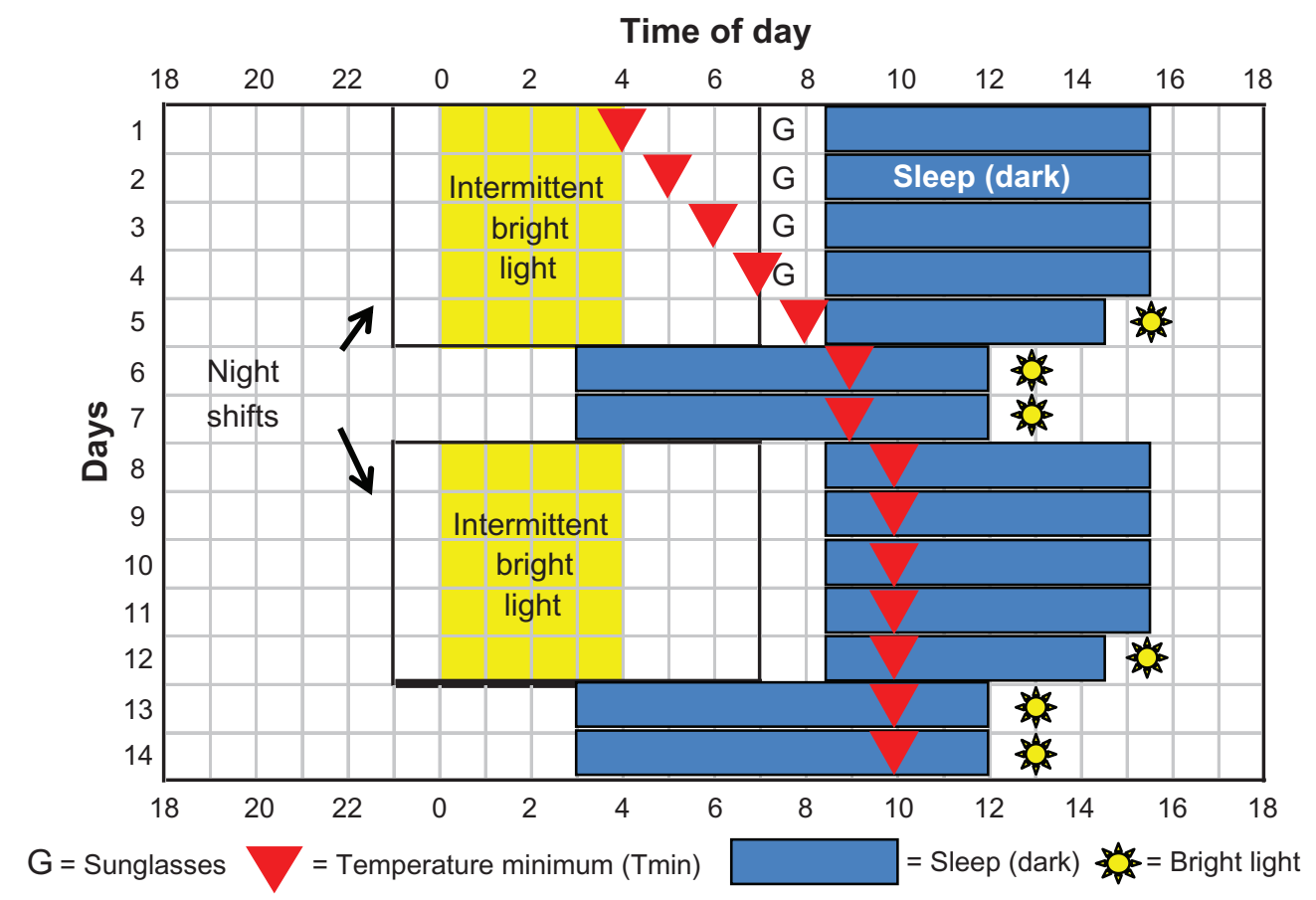

Figure 6 Sleep-and-light schedule designed to reduce the circadian misalignment produced by night-shift work, and thus to improve night-shift performance as well as sleep both after work and on days off.

Notes: A permanent night-shift schedule with 5 days of 8-hour night shifts alternating with 2 days off is shown, but the same principles apply for other times and durations of night shifts (eg, 12 hours) and for other sequences of night shifts and days off. Intermittent bright light is used during the beginning of the night shift to help delay the circadian clock. Blue rectangles indicate sleep in the dark. Days off sleep starts late and extends until noon. Sunglasses (G) are used to attenuate phase-advancing light during the commute home. Bright light (outdoor light or from a light box) is used as indicated by the sun symbols as a light brake to keep the rhythms from delaying too far. The expected course of the circadian clock is shown by the triangles representing the temperature minimum (Tmin), the sleepiest time of day. The exact amount of delaying and advancing bright light needed for an individual must be titrated to ensure that the Tmin reaches and remains within the target zone (the time that sleep after work and sleep on days off overlap). 
Tmin will delay by about 1 hour/day when there is bright light before the Tmin. When the Tmin moves too far away from the night-shift bright light, it will stop shifting because the delaying light exposures will no longer be occurring at a time that facilitates delays; they will be occurring at a less sensitive portion of the delay region of the light PRC. If the Tmin continues to drift later, it will be stopped by the phase-advancing light brake. If the light brake advances it too much, it will be again be nudged in a delaying direction by the bright light during the night shift.

\section{Bright-light exposure during night work}

The setup to deliver bright light during night shifts needs to be adapted to each unique night-work setting. This could be done by ceiling-mounted lights and/or light boxes around an employee's work station. The worker does not have to look directly at the lights. A wide range of commercial light boxes with fluorescent tubes are available for helping to phase-shift the circadian clock. They are usually sold for the treatment of winter depression (seasonal affective disorder or SAD) and a list of some manufacturers is on the website http:// www.sltbr.org. We recommend the larger light boxes, ${ }^{252}$ at least about $50 \mathrm{~cm}$ wide, because they are more pleasant to sit in front of compared to very small, very bright whitelight sources. Also, it is easier to stay within the range of a larger light box than a small light box, which can be easily, inadvertently, angled away from the face and therefore lose effectiveness. However, there are small light-emitting diode (LED) devices that are more practical if space is limited, with the added advantage that they could be more easily moved between work and home. Some light boxes are mounted on stands to aim the light from above, but this can substantially reduce the light level reaching the eyes when a person is looking down, such as while reading.

Some light boxes are enriched in the blue region of the spectrum to which the circadian system is most sensitive. However, we have shown that a blue-enriched polychromatic fluorescent light box $(17,000 \mathrm{~K})$ did not produce significantly greater circadian-rhythm phase shifts than a conventional "white" polychromatic fluorescent light box (4100 K). ${ }^{253,254}$ We have also tested the small goLITE P2 (Philips Consumer Lifestyle, Drachten, the Netherlands) made of blue LEDs in two subjects (unpublished observations) using the same 3-day advancing protocol with morning intermittent light as in some of our other studies. ${ }^{238,255}$ The phase-advance shifts with the GoLite were about 2 hours and fell in the middle of the range of phase shifts obtained with the much larger white fluorescent light box $(\sim 54 \times 54 \mathrm{~cm}$ vs $\sim 11 \times 7 \mathrm{~cm}$ screen size $)$.
We have recently published a light PRC generated with the newer-model goLITE BLU, which shows phase shifts of up to about 2 hours. ${ }^{256}$ The light stimulus was three 30 -minute pulses of blue light ( $\sim 185$ lux $)$ separated by 15 minutes in ordinary room light ( $\sim 30$ lux $)$, administered at the same clock time for 3 consecutive days. Of interest for producing phase delays during night work, the phase-delay portion of this PRC started about 2-3 hours before bedtime and extended through most of the usual nocturnal sleep period. It should be noted that the light was administered in our lab with research assistants present to make sure the light box was aimed properly towards the eyes and at the correct distance $(51 \mathrm{~cm})$. If such tiny light boxes are used in the field, it might be better to use more than one of them. There is a twin-tower light box (Sunnex Biotechnologies, Winnipeg, Canada) with two tall ( $45 \mathrm{~cm}$ high) thin green light boxes fastened together and made to go on each side of a computer screen. One study showed that after one night with the light box on from midnight to 2:00 am ( $\sim 350 \mathrm{lux})$, the phase delay was about 45 minutes more than with dim light $(<10$ lux $){ }^{257}$

\section{Sunglasses}

The times to use sunglasses are shown in Figure 6 (as Gs) when bright light during the commute home occurs after the Tmin and thus would coincide with the phase-advance part of the light PRC and oppose the desired phase delay. Once the Tmin occurs during sleep episodes, sunglasses are no longer needed. Since it will be difficult to tell when an individual's Tmin has delayed far enough, to be safe, the worker should continue to wear sunglasses. There are other advantages to wearing the sunglasses whenever outside in daylight. First, they block harmful ultraviolet (UV) light. Second, they could make the individual more sensitive to the bright light used during the night shift, ${ }^{130}$ thus requiring lower-intensity light to achieve the same delaying effect. We recommend Uvex sunglasses with Bandit adjustable frames and Espresso lenses (15\% light transmission). They are called "blue blockers," but a more precise term would be "blue attenuators." These lenses meet the American National Standards Institute trafficsignal color requirements and are recommended for driving. They are not darker than most sunglasses on the market. See http://www.uvex.com.

Driving home from the night shift is dangerous for night-shift workers, and it could be even more dangerous for workers who follow our sleep-and-light schedule if their Tmin starts out before the travel home time. When the Tmin (the sleepiest time of day) delays through the travel home time, driving performance could be even worse than 
before. But after the Tmin reaches the daytime-sleep episode, alertness and performance while driving home would be expected to improve. Whether driving performance and alertness is at an acceptable safety level when circadian rhythms are partially realigned, and how they compare to the driving performance and alertness of most real night-shift workers whose circadian clocks do not phase-shift, is unknown and should be studied. We recommend that shift workers who adopt our sleep-and-light schedule do not drive home for at least the first week of the schedule, or longer depending on their alertness levels after work. Employers could pay for transportation such as taxis to encourage night workers to attempt a schedule to reduce circadian misalignment.

\section{Sleep (dark) schedule}

In our studies, we used thick black plastic over bedroom windows secured with black masking tape over ordinary masking tape to make experimental subjects' bedrooms completely dark. More professional room-darkening blackout shades could be used by real shift workers. They could also wear eye masks, but some have a tendency to come off during sleep.

Figure 6 has sleep starting 1.5 hours after the end of the night shift, but the sooner the worker can get to bed the better. An earlier bedtime means the Tmin does not have to delay as far to reach daytime sleep, and there is less time between the end of the night shift and bed for light to "hit" the phaseadvance portion of the light PRC and inhibit the desired delay. The worker should avoid all activities that would delay bedtime, such as housework, shopping, child care, and even walking the dog. Overtime and morning meetings should not be tolerated by shift workers, and managerial and administration staff should not ask shift workers to remain on site after the night shift ends. Obviously, the worker will need the cooperation of family and employers in order to get to bed as soon as possible after night work. The sleep (dark) episodes after the night shifts are 7 hours in Figure 6, except for the last sleep in a block, which is 6 hours. As in Figure 1, the purpose of the shorter sleep is to build up a little sleep deprivation so that the worker can fall asleep earlier on days off. However, an individual should be able to cut it shorter or make it longer depending on their needs. The 7-hour sleep episodes could also be a little longer, but we do not recommend making them much shorter.

Sleeping late on days off is one of the most important parts of the schedule and may be the most difficult for workers to adhere to because of social pressures for morning activities. The worker needs to be willing to "give up" their mornings as a protected time for sleep, as long as $\mathrm{s} / \mathrm{he}$ works permanent night shifts, except perhaps on vacations. It may also be necessary to plan late-night activities if others are sleeping. Again, the cooperation of family and friends is essential. With 12-hour shift systems, there are often more than 2 consecutive days off. The worker may not feel the need for 9-hour sleep opportunities on all days off (as in Figure 6), depending on previous sleep deprivation. However, it is still very important to sleep late so that the Tmin is within sleep to enable good sleep, and also to prevent morning light exposure.

A small proportion of the night-shift population already follows the basic sleep schedule we proposed for partial circadian alignment. Gamble et $\mathrm{al}^{258}$ described $14 \%$ of permanent night nurses as "incomplete switchers," because they went to bed and woke up late on days off rather than switching back to more normal earlier sleep times. This group had the lowest prevalence of nurses reporting that they were "not well adapted" to their work schedule (3\%). In addition, although the incomplete switcher group consumed the fewest caffeinated beverages per day, they had the lowest proportion of nurses reporting a moderate or high likelihood of falling asleep during sedentary activities. Three other groups that adopted strategies that involved completely reverting to normally timed nighttime sleep on days off had a much higher prevalence of nurses reporting that they were not well adapted to working nights $(9 \%-22 \%)$. Similarly, Gumenyuk et a ${ }^{259}$ recently reported that a small sample of "asymptomatic" night workers (ie, good sleep quality and no excessive sleepiness) maintained a later sleep schedule on days off, compared to night workers with "shift-work disorder" (ie, insomnia and excessive sleepiness). The circadian rhythms of most of the asymptomatic night workers were delayed by several hours, while the rhythms of the workers with shift-work disorder were similar in phase to day workers.

\section{Afternoon light brake}

This phase-advancing light can be obtained, as in our studies, ${ }^{240-243}$ by going outside in the afternoon. Lighter sunglasses could be worn, as long as they block UV. A light box in workers' homes could be used if outside light exposure was not practical (eg, because of inclement weather).

\section{How much bright light?}

You may be wondering: how much intermittent bright light is necessary during the night shifts? How intense does it have to be? How much bright light is needed for the afternoon light brake? These are difficult questions to answer because 
it depends on the individual's light history, and thus their sensitivity to the phase-shifting effects of light, their circadian phase (Tmin) when starting the sequence of night shifts, and other individual differences. In study 4 , which ended on day 14 in Figure 1, the target zone was reached with only 1 hour of intermittent bright light ( 4000 lux) during each of the night shifts. Once lighting systems are set up in actual shift-work environments, we speculate that getting 1 hour of intermittent bright-light exposure per night shift is actually not that daunting a task.

We know that bright light during the night shift is not absolutely necessary to achieve sufficient partial realignment. Figure 2 showed a control subject who did not get any bright light but delayed enough just by following the recommended sleep schedule and wearing light sunglasses ( $\sim 36 \%$ transmission) on the way home. In one of our simulated night-shift studies, ${ }^{234}$ all the subjects who had baseline Tmin later than the time that the night shift ended showed complete realignment of circadian rhythms after five night shifts, even if they did not get any bright light during the night shifts. But they all adhered to regular sleep (dark) episodes starting soon after work and wore sunglasses when outside. We have also shown that medium-intensity light ( 1230 lux) during night shifts can have as much of a phase-shifting effect as much brighter light ( 5700 lux) ${ }^{218}$ Multiple large light boxes providing medium-intensity light would be more pleasant for the worker than a single tiny bright-white-light box. We believe that as long as the light during the night shift is brighter than indoor light ( $>\sim 500$ lux), then it should have a delaying effect. Nevertheless, we recommend the longest durations and brightest light that is practical for the night-work situation, rather than only relying on the other components of the sleep-and-light schedule, because the light should ensure than the rhythms delay as fast as possible.

One could argue that more research should be done to find out the exact timing, intensity, duration, and wavelengths of light that are needed during the night shift and for the afternoon light brake. While this type of basic research is important and ongoing, it can never provide exact parameters for real shift workers. Given the diversity of work places with different ambient-light levels, individual differences in light sensitivity and thus the magnitude of phase shifts from light, and individual differences in sleep need, there cannot be a one-size-fits-all sleep-and-light schedule. We hope that this review has explained the principles enough so that shift workers and employers can, perhaps with the help of circadian-rhythm experts, devise their own plans. The amount of delaying and advancing bright light may have to be titrated to find the right balance for an individual. This would require careful monitoring, at least keeping a log of light exposure, alertness during night work, alertness between night work and bed, sleep times and sleep quality.

We realize that adopting our sleep-and-light schedule comes at a social cost, and in some situations can be inconvenient. However, working night shifts and attempting to sleep in the daytime or evening without phase-shifting the circadian clock is already socially inconvenient, and carries with it none of the benefits of circadian adaptation. Light boxes, sunglasses, blackout shades and eye masks are much less expensive than the costs of severe circadian misalignment, such as absenteeism, employee turnover, reduced productivity, and impaired health and safety. Finally, developing a health problem (eg, cancer or cardiovascular disease) because of long-term exposure to shift work, or making a mistake on a night shift that results in injury or death, is also decidedly inconvenient and expensive for not only the shift worker but also those around them (eg, family, employer, coworkers) and for society.

The subjects in our studies were not allowed to have caffeine during their night shifts, which is in contrast to the majority of night-shift workers who regularly consume caffeine. As discussed earlier, caffeine improves night-shift alertness and performance, so the addition of caffeine to the sleep-and-light schedule could be beneficial, especially before the target zone has been reached. Caffeine ingested 3 hours before habitual evening bedtime has recently been reported to phase-delay the circadian clock. ${ }^{260}$ The alerting and chronobiotic benefits of appropriately timed caffeine could be a practical adjunct intervention, but would need to be carefully balanced against disruptive effects that caffeine has on daytime sleep, ${ }^{153}$ especially in older individuals. ${ }^{154}$ A small dose of melatonin before daytime sleep could also be useful, especially for its sleep-promoting effect.

\section{Rotating shift work}

There is no way to reduce circadian misalignment for a rapid rotation that includes both night shifts and day shifts, because the circadian clock cannot phase-shift fast enough. This type of shift system is very common, but should be abolished because of the performance, safety, and health problems it creates. However, if the rotation is just between night shifts and evening shifts, then the sleep-and-light schedule shown in Figure 6 can be applied. Sleep times before evening shifts can be the same as on days off, and the afternoon light brake can be obtained on the way to work for the evening shift as well as in the afternoons on days off. 
A rotation between day and evening shifts is another option that can produce less circadian misalignment than a rotation that includes both day shifts and night shifts. In this case, the worker's sleep schedule would be like that adopted by most high school students, college students, and the young day-working population who go to bed and wake up 2-3 hours later on weekends (days off) than on work or school days, producing social jet lag. ${ }^{52,261-263}$ The shift worker would go to bed and wake up earlier before day shifts, and go to bed and wake up later before evening shifts and days off. Although social jet lag is a serious problem, it is not as extreme as the circadian misalignment that accompanies night work.

Finally, it is possible to practically eliminate circadian misalignment with a three-shift system if there is a slowly rotating schedule that rotates in the delaying direction (eg, 2 weeks of days, 2 weeks of evenings, 2 weeks of nights, and so on). Then it is possible to delay both the sleep schedule and the circadian rhythms so that they remain fairly well aligned. See Figure 3 in Eastman ${ }^{264}$ for the general idea. However, the worker would need to get delaying bright light or sunlight before bed on a few of the days in each cycle in order to keep the circadian clock delaying as fast as necessary. Scheduling social and family events would require careful planning, but some workers might prefer it to permanent night shifts.

It is time to take creative, bold steps towards solving the serious problems produced by night-shift work.

\section{Acknowledgments}

The studies referred to in this review as ours were performed in the Biological Rhythms Research Laboratory of Rush University Medical Center in Chicago, and were primarily supported by grant R01OH003954 from the National Institute of Occupational Safety and Health (NIOSH) of the Centers for Disease Control and Prevention (CDC) and also by grants from the National Institutes of Health (R01NS23421, R01NS35695, R01NR07677, R01HL086934) to Charmane Eastman. The content is solely the responsibility of the authors and does not necessarily represent the official views of the granting institutions: the National Institute of Occupational Safety and Health and the National Institutes of Health. These institutes had no involvement in designing the studies, data collection, data analysis and interpretation, or the writing of this manuscript. The authors have no conflicts of interest and did not receive any funds or salary support for writing this manuscript. We thank Daniel L Johnson, MD, for plodding through an earlier draft and providing tips for writing science for a lay audience.

\section{Disclosure}

The authors report no conflicts of interest in this work.

\section{References}

1. Ha M, Park J. Shiftwork and metabolic risk factors of cardiovascular disease. J Occup Health. 2005;47:89-95.

2. Biggi N, Consonni D, Galluzzo V, Sogliani M, Costa G. Metabolic syndrome in permanent night workers. Chronobiol Int. 2008;25: 443-454.

3. Ghiasvand M, Heshmat R, Golpira R, et al. Shift working and risk of lipid disorders: a cross-sectional study. Lipids Health Dis. 2006;5:9.

4. Karlsson BH, Knutsson AK, Lindahl BO, Alfredsson LS. Metabolic disturbances in male workers with rotating three-shift work. Results of the WOLF study. Int Arch Occup Environ Health. Jul 2003;76: 424-430.

5. Karlsson B, Knutsson A, Lindahl B. Is there an association between shift work and having a metabolic syndrome? Results from a population based study of 27,485 people. Occup Environ Med. 2001;58:747-752.

6. De Bacquer D, Van Risseghem M, Clays E, Kittel F, De Backer G, Braeckman L. Rotating shift work and the metabolic syndrome: a prospective study. Int J Epidemiol. 2009;38:848-854.

7. Knutsson A, Akerstedt T, Jonsson BG. Prevalence of risk factors for coronary artery disease among day and shift workers. Scand J Work Environ Health. 1988;14:317-321.

8. Nagaya T, Yoshida H, Takahashi H, Kawai M. Markers of insulin resistance in day and shift workers aged 30-59 years. Int Arch Occup Environ Health. 2002;75:562-568.

9. Romon M, Nuttens MC, Fievet C, et al. Increased triglyceride levels in shift workers. Am J Med. 1992;93:259-262.

10. Suwazono Y, Dochi M, Sakata K, et al. Shift work is a risk factor for increased blood pressure in Japanese men: a 14-year historical cohort study. Hypertension. 2008;52:581-586.

11. Oishi M, Suwazono Y, Sakata K, et al. A longitudinal study on the relationship between shift work and the progression of hypertension in male Japanese workers. J Hypertens. 2005;23:2173-2178.

12. Ohira T, Tanigawa T, Iso H, et al. Effects of shift work on 24-hour ambulatory blood pressure and its variability among Japanese workers. Scand J Work Environ Health. 2000;26:421-426.

13. Yamasaki F, Schwartz JE, Gerber LM, Warren K, Pickering TG. Impact of shift work and race/ethnicity on the diurnal rhythm of blood pressure and catecholamines. Hypertension. 1998;32:417-423.

14. Lin YC, Hsiao TJ, Chen PC. Persistent rotating shift-work exposure accelerates development of metabolic syndrome among middleaged female employees: a five-year follow-up. Chronobiol Int. 2009;26:740-755.

15. Drake CL, Roehrs T, Richardson G, Walsh JK, Roth T. Shift work sleep disorder: prevalence and consequences beyond that of symptomatic day workers. Sleep. 2004;27:1453-1462.

16. Brown DL, Feskanich D, Sanchez BN, Rexrode KM, Schernhammer ES, Lisabeth LD. Rotating night shift work and the risk of ischemic stroke. Am J Epidemiol. 2009;169:1370-1377.

17. Li Y, Sato Y, Yamaguchi N. Shift work and the risk of metabolic syndrome: a nested case-control study. Int J Occup Environ Health. 2011;17:154-160.

18. Fujino Y, Iso H, Tamakoshi A, et al. A prospective cohort study of shift work and risk of ischemic heart disease in Japanese male workers. $\mathrm{Am}$ J Epidemiol. 2006;164:128-135.

19. Lieu SJ, Curhan GC, Schernhammer ES, Forman JP. Rotating night shift work and disparate hypertension risk in African-Americans. J Hypertens. 2012;30:61-66.

20. Knutsson A, Boggild H. Gastrointestinal disorders among shift workers. Scand J Work Environ Health. 2010;36:85-95.

21. Nojkov B, Rubenstein JH, Chey WD, Hoogerwerf WA. The impact of rotating shift work on the prevalence of irritable bowel syndrome in nurses. Am J Gastroenterol. 2010;105:842-847. 
22. Lu W, Gwee K, Ho K. Functional bowel disorders in rotating shift nurses may be related to sleep disturbances. Eur J Gastroenterol Hepatol. 2006;18:623-627.

23. Segawa K, Nakazawa S, Tsukamoto Y, et al. Peptic ulcer is prevalent among shift workers. Dig Dis Sci. 1987;32:449-453.

24. Saberi HR, Moravveji AR. Gastrointestinal complaints in shift-working and day-working nurses in Iran. J Circadian Rhythms. 2010;8:9.

25. Lund J, Arendt J, Hampton SM, English J, Morgan LM. Postprandial hormone and metabolic responses amongst shift workers in Antarctica. J Endocrinol. 2001;171:557-564.

26. Pan A, Schernhammer ES, Sun Q, Hu FB. Rotating night shift work and risk of type 2 diabetes: two prospective cohort studies in women. PLoS Med. 2011;8:e1001141.

27. Bisanti L, Olsen J, Basso O, Thonneau P, Karmaus W. Shift work and subfecundity: a European multicenter study. J Occup Environ Med. 1996;38:352-358.

28. Uehata T, Sasakawa N. The fatigue and maternity disturbances of night workwomen. J Hum Ergol (Tokyo). 1982;11 Suppl:465-474.

29. Xu X, Ding M, Li B, Christiani DC. Association of rotating shiftwork with preterm births and low birth weight among never smoking women textile workers in China. Occup Environ Med. 1994;51: $470-474$.

30. Ahlborg G Jr, Axelsson G, Bodin L. Shift work, nitrous oxide exposure and subfertility among Swedish midwives. Int J Epidemiol. 1996;25:783-790.

31. Axelsson G, Lutz C, Rylander R. Exposure to solvents and outcome of pregnancy in university laboratory employees. $\mathrm{Br} J$ Ind $\mathrm{Med}$. 1984;41:305-312.

32. Axelsson G, Ahlborg G Jr, Bodin L. Shift work, nitrous oxide exposure, and spontaneous abortion among Swedish midwives. Occup Environ Med. 1996;53:374-378.

33. Axelsson G, Rylandfer R, Molin I. Outcome of pregnancy in relation to irregular and inconvenient work schedules. $\mathrm{Br} J$ Ind Med. 1989;46:393-398.

34. McDonald AD, McDonald JC, Armstrong B, et al. Fetal death and work in pregnancy. Br J Ind Med. 1988;45:148-157.

35. Marino JL, Holt VL, Chen C, Davis S. Shift work, hCLOCK T3111C polymorphism, and endometriosis risk. Epidemiology. 2008;19: 477-484.

36. Suwazono Y, Dochi M, Sakata K, et al. A longitudinal study on the effect of shift work on weight gain in male Japanese workers. Obesity (Silver Spring). 2008;16:1887-1893.

37. Di Lorenzo L, De Pergola G, Zocchetti C, et al. Effect of shift work on body mass index: results of a study performed in 319 glucose-tolerant men working in a Southern Italian industry. Int J Obes Relat Metab Disord. 2003;27:1353-1358.

38. Morikawa Y, Nakagawa H, Miura K, et al. Effect of shift work on body mass index and metabolic parameters. Scand J Work Environ Health. 2007;33:45-50.

39. Kawachi I, Colditz GA, Stampfer MJ, et al. Prospective study of shift work and risk of coronary heart disease in women. Circulation. 1995;92:3178-3182.

40. van Amelsvoort LG, Schouten EG, Kok FJ. Duration of shiftwork related to body mass index and waist to hip ratio. Int J Obes Relat Metab Disord. 1999;23:973-978.

41. Macagnan J, Pattussi MP, Canuto R, Henn RL, Fassa AG, Olinto MT. Impact of nightshift work on overweight and abdominal obesity among workers of a poultry processing plant in southern Brazil. Chronobiol Int. 2012;29:336-343.

42. Viswanathan AN, Hankinson SE, Schernhammer ES. Night shift work and the risk of endometrial cancer. Cancer Res. 2007;67:10618-10622.

43. Schernhammer ES, Laden F, Speizer FE, et al. Night-shift work and risk of colorectal cancer in the nurses' health study. J Natl Cancer Inst. 2003;95:825-828.

44. Kubo T, Ozasa K, Mikami K, et al. Prospective cohort study of the risk of prostate cancer among rotating-shift workers: findings from the Japan collaborative cohort study. Am J Epidemiol. 2006;164:549-555.
45. Hansen J, Stevens RG. Case-control study of shift-work and breast cancer risk in Danish nurses: impact of shift systems. Eur J Cancer. 2011;48:1722-1729.

46. Schernhammer ES, Kroenke CH, Laden F, Hankinson SE. Night work and risk of breast cancer. Epidemiology. 2006;17:108-111.

47. Davis S, Mirick DK, Stevens RG. Night shift work, light at night, and risk of breast cancer. J Natl Cancer Inst. 2001;93:1557-1562.

48. Hansen J. Increased breast cancer risk among women who work predominantly at night. Epidemiology. 2001;12:74-77.

49. Straif K, Baan R, Grosse Y, et al. Carcinogenicity of shift-work, painting, and fire-fighting. Lancet Oncol. 2007;8:1065-1066.

50. Schernhammer ES, Laden F, Speizer FE, et al. Rotating night shifts and risk of breast cancer in women participating in the nurses' health study. J Natl Cancer Inst. 2001;93:1563-1568.

51. Pilcher JJ, Lambert BJ, Huffcutt AI. Differential effects of permanent and rotating shifts on self-report sleep length: a meta-analytic review. Sleep. 2000;23:155-163.

52. Roenneberg T, Allebrandt KV, Merrow M, Vetter C. Social jetlag and obesity. Curr Biol. 2012;22:939-943.

53. Monk TH. What can the chronobiologist do to help the shift worker? J Biol Rhythms. 2000;15:86-94.

54. Aschoff J, von Saint Paul U, Wever RA. Lifetime of flies under influence of time displacement. Naturwissenschaften. 1971;58:574. German

55. Pittendrigh CS, Minis DH. Circadian systems: longevity as a function of circadian resonance in Drosophila melanogaster. Proc Natl Acad Sci U S A. 1972;69:1537-1539.

56. von Saint Paul U, Aschoff J. Longevity among blowflies Phormia terraenovae R. D. kept in non-24-hour light-dark cycles. J Comp Physiol A Neuroethol Sens Neural Behav Physiol. 1978;127:191-195.

57. Davidson AJ, Sellix MT, Daniel J, Yamazaki S, Menaker M, Block GD. Chronic jet-lag increases mortality in aged mice. Curr Biol. 2006;16:R914-R916.

58. Kort WJ, Weijma JM. Effect of chronic light-dark shift stress on the immune response of the rat. Physiol Behav. 1982;29:1083-1087.

59. Filipski E, Delaunay F, King VM, et al. Effects of chronic jet lag on tumor progression in mice. Cancer Res. 2004;64:7879-7885.

60. Preuss F, Tang Y, Laposky AD, Arble D, Keshavarzian A, Turek FW. Adverse effects of chronic circadian desynchronization in animals in a "challenging" environment. Am J Physiol Regul Integr Comp Physiol. 2008;295:R2034-R2040.

61. Martino TA, Tata N, Belsham DD, et al. Disturbed diurnal rhythm alters gene expression and exacerbates cardiovascular disease with rescue by resynchronization. Hypertension. 2007;49:1104-1113.

62. Martino TA, Oudit GY, Herzenberg AM, et al. Circadian rhythm disorganization produces profound cardiovascular and renal disease in hamsters. Am J Physiol Regul Integr Comp Physiol. 2008;294:R1675-R1683.

63. Penev PD, Kolker DE, Zee PC, Turek FW. Chronic circadian desynchronization decreases the survival of animals with cardiomyopathic heart disease. Am J Physiol. 1998;275:H2334-H2337.

64. Karatsoreos IN, Bhagat S, Bloss EB, Morrison JH, McEwen BS. Disruption of circadian clocks has ramifications for metabolism, brain, and behavior. Proc Natl Acad Sci U S A. 2011;108:1657-1662.

65. Varcoe TJ, Wight N, Voultsios A, Salkeld MD, Kennaway DJ. Chronic phase shifts of the photoperiod throughout pregnancy programs glucose intolerance and insulin resistance in the rat. PLoS One. 2011;6:e18504.

66. Fonken LK, Workman JL, Walton JC, et al. Light at night increases body mass by shifting the time of food intake. Proc Natl Acad Sci U S A. 2010;107:18664-18669.

67. Lee S, Donehower LA, Herron AJ, Moore DD, Fu L. Disrupting circadian homeostasis of sympathetic signaling promotes tumor development in mice. PLoS One. 2010;5:e10995.

68. Logan RW, Zhang C, Murugan S, et al. Chronic shift-lag alters the circadian clock of NK cells and promotes lung cancer growth in rats. J Immunol. 2012;188:2583-2591. 
69. Scheer FA, Hilton MF, Mantzoros CS, Shea SA. Adverse metabolic and cardiovascular consequences of circadian misalignment. Proc Natl Acad Sci U S A. 2009;106:4453-4458.

70. Zulley J, Wever R, Aschoff J. The dependence of onset and duration of sleep on the circadian rhythm of rectal temperature. Pflugers Arch. 1981;391:314-318.

71. Strogatz SH, Kronauer RE, Czeisler CA. Circadian regulation dominates homeostatic control of sleep length and prior wake length in humans. Sleep. 1986;9:353-364.

72. Wyatt JK, Ritz-De Cecco A, Czeisler CA, Dijk DJ. Circadian temperature and melatonin rhythms, sleep, and neurobehavioral function in humans living on a 20-h day. Am J Physiol. 1999;277:R1152-R1163.

73. Dumont M, Benhaberou-Brun D, Paquet J. Profile of 24-h light exposure and circadian phase of melatonin secretion in night workers. $J$ Biol Rhythms. 2001;16:502-511.

74. Koller M, Harma M, Laitinen JT, Kundi M, Piegler B, Haider M. Different patterns of light exposure in relation to melatonin and cortisol rhythms and sleep of night workers. J Pineal Res. 1994;16:127-135.

75. Roden M, Koller M, Pirich K, Vierhapper H, Waldhauser F. The circadian melatonin and cortisol secretion pattern in permanent night shift workers. Am J Physiol. 1993;265:R261-R267.

76. Sack RL, Blood ML, Lewy AJ. Melatonin rhythms in night shift workers. Sleep. 1992;15:434-441.

77. Weibel L, Spiegel K, Gronfier C, Follenius M, Brandenberger G. Twenty-four-hour melatonin and core body temperature rhythms: their adaptation in night workers. Am J Physiol. 1997;272:R948-R954.

78. Eastman CI, Boulos Z, Terman M, Campbell SS, Dijk DJ, Lewy AJ. Light treatment for sleep disorders: consensus report. VI. Shift work. J Biol Rhythms. 1995;10:157-164.

79. Ferguson SA, Kennaway DJ, Baker A, Lamond N, Dawson D. Sleep and circadian rhythms in mining operators: limited evidence of adaptation to night shifts. Appl Ergon. 2011;43:695-701.

80. Grundy A, Sanchez M, Richardson H, et al. Light intensity exposure, sleep duration, physical activity, and biomarkers of melatonin among rotating shift nurses. Chronobiol Int. 2009;26:1443-1461.

81. Grundy A, Tranmer J, Richardson H, Graham CH, Aronson KJ. The influence of light at night exposure on melatonin levels among Canadian rotating shift nurses. Cancer Epidemiol Biomarkers Prev. 2011;20:2404-2412.

82. Burch JB, Yost MG, Johnson W, Allen E. Melatonin, sleep, and shift work adaptation. J Occup Environ Med. 2005;47:893-901.

83. Quera-Salva MA, Defrance R, Claustrat B, De Lattre J, Guilleminault C. Rapid shift in sleep time and acrophase of melatonin secretion in short shift work schedule. Sleep. 1996;19:539-543.

84. Folkard S. Do permanent night workers show circadian adjustment? A review based on the endogenous melatonin rhythm. Chronobiol Int. 2008;25:215-224.

85. Akerstedt T. Shift work and disturbed sleep/wakefulness. Occup Med (Lond). 2003;53:89-94.

86. Akerstedt T, Wright K. Sleep loss and fatigue in shift work and shift work disorder. Sleep Med Clin. 2009;4:257-271.

87. Spiegel K, Sheridan JF, Van Cauter E. Effect of sleep deprivation on response to immunization. JAMA. 2002;288:1471-1472.

88. Spiegel K, Leproult R, Van Cauter E. Impact of sleep debt on metabolic and endocrine function. Lancet. 1999;354:1435-1439.

89. Buxton OM, Pavlova M, Reid EW, Wang W, Simonson DC, Adler GK. Sleep restriction for 1 week reduces insulin sensitivity in healthy men. Diabetes. 2010;59:2126-2133.

90. Schmid SM, Hallschmid M, Jauch-Chara K, et al. Disturbed glucoregulatory response to food intake after moderate sleep restriction. Sleep. 2011;34:371-377.

91. Gottlieb DJ, Punjabi NM, Newman AB, et al. Association of sleep time with diabetes mellitus and impaired glucose tolerance. Arch Intern Med. 2005; 165:863-867.

92. Cappuccio FP, Taggart FM, Kandala NB, et al. Meta-analysis of short sleep duration and obesity in children and adults. Sleep. 2008;31:619-626.
93. Gottlieb DJ, Redline S, Nieto FJ, et al. Association of usual sleep duration with hypertension: the Sleep Heart Health Study. Sleep. 2006;29:1009-1014.

94. Wolff B, Volzke H, Schwahn C, Robinson D, Kessler C, John U. Relation of self-reported sleep duration with carotid intima-media thickness in a general population sample. Atherosclerosis. 2008;196: 727-732.

95. Knutson KL, Van Cauter E, Rathouz PJ, et al. Association between sleep and blood pressure in midlife: the CARDIA sleep study. Arch Intern Med. 2009;169:1055-1061.

96. King CR, Knutson KL, Rathouz PJ, Sidney S, Liu K, Lauderdale DS. Short sleep duration and incident coronary artery calcification. JAMA. 2008;300:2859-2866.

97. Cappuccio FP, Stranges S, Kandala NB, et al. Gender-specific associations of short sleep duration with prevalent and incident hypertension: the Whitehall II Study. Hypertension. 2007;50:693-700.

98. Stranges S, Dorn JM, Cappuccio FP, et al. A population-based study of reduced sleep duration and hypertension: the strongest association may be in premenopausal women. J Hypertens. 2010;28:896-902.

99. Cappuccio FP, Cooper D, D’Elia L, Strazzullo P, Miller MA. Sleep duration predicts cardiovascular outcomes: a systematic review and meta-analysis of prospective studies. Eur Heart J. 2011;32: 1484-1492.

100. Cappuccio FP, D'Elia L, Strazzullo P, Miller MA. Quantity and quality of sleep and incidence of type 2 diabetes: a systematic review and meta-analysis. Diabetes Care. 2010;33:414-420.

101. von Kries R, Toschke AM, Wurmser H, Sauerwald T, Koletzko B. Reduced risk for overweight and obesity in 5- and 6-y-old children by duration of sleep - a cross-sectional study. Int J Obes Relat Metab Disord. 2002;26:710-716.

102. Rutters F, Gerver WJ, Nieuwenhuizen AG, Verhoef SP, WesterterpPlantenga MS. Sleep duration and body-weight development during puberty in a Dutch children cohort. Int $J$ Obes (Lond). 2010;34:1508-1514.

103. Ayas NT, White DP, Manson JE, et al. A prospective study of sleep duration and coronary heart disease in women. Arch Intern Med. 2003;163:205-209.

104. Ayas NT, White DP, Al-Delaimy WK, et al. A prospective study of self-reported sleep duration and incident diabetes in women. Diabetes Care. 2003;26:380-384.

105. Yaggi HK, Araujo AB, McKinlay JB. Sleep duration as a risk factor for the development of type 2 diabetes. Diabetes Care. 2006;29:657-661.

106. Mallon L, Broman JE, Hetta J. High incidence of diabetes in men with sleep complaints or short sleep duration: a 12-year follow-up study of a middle-aged population. Diabetes Care. 2005;28:2762-2767.

107. Chaput JP, Despres JP, Bouchard C, Astrup A, Tremblay A. Sleep duration as a risk factor for the development of type 2 diabetes or impaired glucose tolerance: analyses of the Quebec Family Study. Sleep Med. 2009;10:919-924.

108. Chaput JP, Despres JP, Bouchard C, Tremblay A. Association of sleep duration with type 2 diabetes and impaired glucose tolerance. Diabetologia. 2007;50:2298-2304.

109. Hoevenaar-Blom MP, Spijkerman AM, Kromhout D, van den Berg JF, Verschuren WM. Sleep duration and sleep quality in relation to 12-year cardiovascular disease incidence: the MORGEN study. Sleep. 2011;34:1487-1492.

110. Buxton OM, Cain SW, O'Connor SP, et al. Adverse metabolic consequences in humans of prolonged sleep restriction combined with circadian disruption. Sci Transl Med. 2012;4:129ra143.

111. Nguyen J, Wright K. Influence of weeks of circadian misalignment on leptin levels. Nat Sci Sleep. 2010;2:9-18.

112. Lewy AJ, Wehr TA, Goodwin FK, Newsome DA, Markey SP. Light suppresses melatonin secretion in humans. Science. 1980;210: 1267-1269.

113. Bojkowski CJ, Aldhous ME, English J, et al. Suppression of nocturnal plasma melatonin and 6-sulphatoxymelatonin by bright and dim light in man. Horm Metab Res. 1987;19:437-440. 
114. Trinder J, Armstrong SM, O’Brien C, Luke D, Martin MJ. Inhibition of melatonin secretion onset by low levels of illumination. J Sleep Res. 1996;5:77-82.

115. Aoki H, Yamada N, Ozeki Y, Yamane H, Kato N. Minimum light intensity required to suppress nocturnal melatonin concentration in human saliva. Neurosci Lett. 1998;252:91-94.

116. Zeitzer JM, Dijk DJ, Kronauer RE, Brown EN, Czeisler CA. Sensitivity of the human circadian pacemaker to nocturnal light: melatonin phase resetting and suppression. J Physiol. 2000;526:695-702.

117. Reiter RJ. Mechanisms of cancer inhibition by melatonin. J Pineal Res. 2004;37:213-214.

118. Viswanathan AN, Schernhammer ES. Circulating melatonin and the risk of breast and endometrial cancer in women. Cancer Lett. 2009;281:1-7.

119. Schernhammer ES, Schulmeister K. Melatonin and cancer risk: does light at night compromise physiologic cancer protection by lowering serum melatonin levels? Br J Cancer. 2004;90:941-943.

120. Sasseville A, Paquet N, Sevigny J, Hebert M. Blue blocker glasses impede the capacity of bright light to suppress melatonin production. J Pineal Res. 2006;41:73-78.

121. Kayumov L, Casper RF, Hawa RJ, et al. Blocking low-wavelength light prevents nocturnal melatonin suppression with no adverse effect on performance during simulated shift work. J Clin Endocrinol Metab. 2005;90:2755-2761.

122. Kayumov L, Lowe A, Rahman SA, Casper RF, Shapiro CM. Prevention of melatonin suppression by nocturnal lighting: relevance to cancer. Eur J Cancer Prev. 2007;16:357-362.

123. Rahman SA, Marcu S, Shapiro CM, Brown TJ, Casper RF. Spectral modulation attenuates molecular, endocrine, and neurobehavioral disruption induced by nocturnal light exposure. Am J Physiol Endocrinol Metab. 2011;300:E518-E527.

124. Davis S, Mirick DK, Chen C, Stanczyk FZ. Night shift work and hormone levels in women. Cancer Epidemiol Biomarkers Prev. 2012;21:609-618.

125. Marie Hansen A, Helene Garde A, Hansen J. Diurnal urinary 6-sulfatoxymelatonin levels among healthy Danish nurses during work and leisure time. Chronobiol Int. 2006;23:1203-1215.

126. Yamauchi H. Effects of night work on urinary excretion rates of 6-sulfatoxymelatonin, norepinephrine and estriol in pregnant women. Ind Health. 2004;42:268-276.

127. Peplonska B, Bukowska A, Gromadzinska J, et al. Night shift work characteristics and 6-sulfatoxymelatonin (MT6s) in rotating night shift nurses and midwives. Occup Environ Med. 2012;69:339-346.

128. Schernhammer ES, Kroenke CH, Dowsett M, Folkerd E, Hankinson SE. Urinary 6-sulfatoxymelatonin levels and their correlations with lifestyle factors and steroid hormone levels. J Pineal Res. 2006;40: 116-124.

129. Dumont M, Lanctot V, Cadieux-Viau R, Paquet J. Melatonin production and light exposure of rotating night workers. Chronobiol Int. 2012;29:203-210.

130. Hebert M, Martin SK, Lee C, Eastman CI. The effects of prior light history on the suppression of melatonin by light in humans. J Pineal Res. 2002;33:198-203.

131. Rufiange M, Beaulieu C, Lachapelle P, Dumont M. Circadian light sensitivity and rate of retinal dark adaptation in indoor and outdoor workers. J Biol Rhythms. 2007;22:454-457.

132. Smith KA, Schoen MW, Czeisler CA. Adaptation of human pineal melatonin suppression by recent photic history. J Clin Endocrinol Metab. 2004;89:3610-3614.

133. Burgess HJ, Fogg LF. Individual differences in the amount and timing of salivary melatonin secretion. PLoS One. 2008;3:e3055.

134. Arendt J. Shift work: coping with the biological clock. Occup Med (Lond). 2010;60:10-20.

135. Akerstedt T. Sleepiness as a consequence of shift work. Sleep. 1988;11:17-34.

136. Akerstedt T. Work hours, sleepiness and the underlying mechanisms. J Sleep Res. 1995;4:15-22.
137. Folkard S, Akerstedt T. Trends in the risk of accidents and injuries and their implications for models of fatigue and performance. Aviat Space Environ Med. 2004;75:A161-A167.

138. Akerstedt T, Torsvall L, Gillberg M. Sleepiness and shift work: field studies. Sleep. 1982;5:S95-S106.

139. Akerstedt T, Czeisler CA, Dinges DF, Horne JA. Accidents and sleepiness: a consensus statement from the International Conference on Work Hours, Sleepiness and Accidents, Stockholm, September 8-10, 1994. J Sleep Res. 1994;3:195.

140. Barger LK, Lockley SW, Rajaratnam SM, Landrigan CP. Neurobehavioral, health, and safety consequences associated with shift work in safety-sensitive professions. Curr Neurol Neurosci Rep. 2009;9:155-164.

141. Cohen DA, Wang W, Wyatt JK, et al. Uncovering residual effects of chronic sleep loss on human performance. Sci Transl Med. 2010;2:14ra13.

142. Walsh JK, Muehlbach MJ, Humm TM, Dickins QS, Sugerman JL, Schweitzer PK. Effect of caffeine on physiological sleep tendency and ability to sustain wakefulness at night. Psychopharmacology. 1990;101:271-273.

143. Schweitzer PK, Randazzo AC, Stone K, Erman M, Walsh JK. Laboratory and field studies of naps and caffeine as practical countermeasures for sleep-wake problems associated with night work. Sleep. 2006;29:39-50.

144. Schweitzer PK, Muehlbach MJ, Walsh JK. Countermeasures for night work performance deficits: the effect of napping or caffeine on continuous performance at night. Work Stress. 1992;6:355-365.

145. Muehlbach MJ, Walsh JK. The effects of caffeine on simulated nightshift work and subsequent daytime sleep. Sleep. 1995;18:22-29.

146. Wright KP, Badia P, Myers BL, Plenzler SC. Combination of bright light and caffeine as a countermeasure for impaired alertness and performance during extended sleep deprivation. J. Sleep Res. 1997;6:26-35.

147. Borland RG, Rogers AS, Nicholson AN, Pascoe PA, Spencer MB. Performance overnight in shiftworkers operating a day-night schedule. Aviat Space Environ Med. 1986;57:241-249.

148. Bonnet MH, Gomez S, Wirth O, Arand DL. The use of caffeine versus prophylactic naps in sustained performance. Sleep. 1995;18:97-104.

149. Ker K, Edwards PJ, Felix LM, Blackhall K, Roberts I. Caffeine for the prevention of injuries and errors in shift workers. Cochrane Database Syst Rev. 2010;5:CD008508.

150. Rogers AS, Spencer MB, Stone BM, Nicholson AN. The influence of a 1 h nap on performance overnight. Ergonomics. 1989;32: 1193-1205.

151. Smith AP, Brockman P, Flynn R, Maben A, Thomas M. Investigation of the effects of coffee on alertness and performance during the day and night. Neuropsychobiology. 1993;27:217-223.

152. Babkoff H, French J, Whitmore J, Sutherlin R. Single-dose bright light and/or caffeine effect on nocturnal performance. Aviat Space Environ Med. 2002;73:341-350.

153. Carrier J, Fernandez-Bolanos M, Robillard R, et al. Effects of caffeine are more marked on daytime recovery sleep than on nocturnal sleep. Neuropsychopharmacology. 2007;32:964-972.

154. Carrier J, Paquet J, Fernandez-Bolanos M, et al. Effects of caffeine on daytime recovery sleep: a double challenge to the sleep-wake cycle in aging. Sleep Med. 2009;10:1016-1024.

155. Walsh JK, Randazzo AC, Stone KL, Schweitzer PK. Modafinil improves alertness, vigilance, and executive function during simulated night shifts. Sleep. 2004;27:434-439.

156. Hart CL, Haney M, Vosburg SK, Comer SD, Gunderson E, Foltin RW. Modafinil attenuates disruptions in cognitive performance during simulated night-shift work. Neuropsychopharmacology. 2006;31: 1526-1536.

157. Czeisler CA, Walsh JK, Wesnes KA, Arora S, Roth T. Armodafinil for treatment of excessive sleepiness associated with shift work disorder: a randomized controlled study. Mayo Clin Proc. 2009;84: 958-972. 
158. Czeisler CA, Walsh JK, Roth T, et al. Modafinil for excessive sleepiness associated with shift-work sleep disorder. $N$ Engl J Med. 2005;353:476-486.

159. Van Dongen HPA, Maislin G, Mullington JM, Dinges DF. The cumulative cost of additional wakefulness: dose-response effects on neurobehavioral functions and sleep physiology from chronic sleep restriction and total sleep deprivation. Sleep. 2003;26: 117-126.

160. Walsh JK, Schweitzer PK, Anch AM, Muehlbach MJ, Jenkins NA, Dickins QS. Sleepiness/alertness on a simulated night shift following sleep at home with triazolam. Sleep. 1991;14:140-146.

161. Walsh JK, Sugerman JL, Muehlbach MJ, Schweitzer PK. Physiological sleep tendency on a simulated night shift: adaptation and effects of triazolam. Sleep. 1988;11:251-264.

162. Walsh JK, Muehlbach MJ, Schweitzer PK. Hypnotics and caffeine as countermeasures for shiftwork-related sleepiness and sleep disturbance. J Sleep Res. 1995;4:80-83.

163. Schweitzer PK, Koshorek G, Muehlbach MJ, et al. Effects of estazolam and triazolam on transient insomnia associated with phase-shifted sleep. Hum Psychopharmacol. 1991;6:99-107.

164. Dawson D, Campbell SS. Timed exposure to bright light improves sleep and alertness during simulated night shifts. Sleep. 1991;14:511-516.

165. Gaudreau H, Morettini J, Lavoie HB, Carrier J. Effects of a 25-h sleep deprivation on daytime sleep in the middle-aged. Neurobiol Aging. 2001;22:461-468.

166. Dijk DJ, Duffy JF, Czeisler CA. Age-related increase in awakenings: impaired consolidation of nonREM sleep at all circadian phases. Sleep. 2001;24:565-577.

167. Silva EJ, Wang W, Ronda JM, Wyatt JK, Duffy JF. Circadian and wake-dependent influences on subjective sleepiness, cognitive throughput, and reaction time performance in older and young adults. Sleep. 2010;33:481-490.

168. Adam M, Retey JV, Khatami R, Landolt HP. Age-related changes in the time course of vigilant attention during 40 hours without sleep in men. Sleep. 2006;29:55-57.

169. Lewy AJ, Ahmed S, Jackson JML, Sack RL. Melatonin shifts human circadian rhythms according to a phase-response curve. Chronobiol Int. 1992;9:380-392.

170. Sack RL, Hughes RJ, Edgar DM, Lewy AJ. Sleep-promoting effects of melatonin: at what dose, in whom, under what conditions, and by what mechanisms? Sleep. 1997;20:908-915.

171. Folkard S, Arendt J, Clark M. Can melatonin improve shift workers' tolerance of the night shift? Some preliminary findings. Chronobiol Int. 1993;10:315-320.

172. Sharkey KM, Fogg LF, Eastman CI. Effects of melatonin administration on daytime sleep after simulated night shift work. J Sleep Res. 2001;10:181-192.

173. Smith MR, Lee C, Crowley SJ, Fogg LF, Eastman CI. Morning melatonin has limited benefit as a soporific for daytime sleep after night work. Chronobiol Int. 2005;22:873-888.

174. Dawson D, Encel N, Lushington K. Improving adaptation to simulated night shift: timed exposure to bright light versus daytime melatonin administration. Sleep. 1995;18:11-21.

175. Aeschbach D, Lockyer BJ, Dijk DJ, et al. Use of transdermal melatonin delivery to improve sleep maintenance during daytime. Clin Pharmacol Ther. 2009;86:378-382.

176. Jorgensen KM, Witting MD. Does exogenous melatonin improve day sleep or night alertness in emergency physicians working night shifts? Ann Emerg Med. 1998;31:699-704.

177. Jockovich M, Cosentino D, Cosentino L, Wears RL, Seaberg DC. Effect of exogenous melatonin on mood and sleep efficiency in emergency medicine residents working night shifts. Acad Emerg Med. 2000;7:955-958.

178. James M, Tremea MO, Jones JS, Krohmer JR. Can melatonin improve adaptation to night shift? Am J Emerg Med. 1998;16:367-370.
179. Smith-Coggins R, Howard SK, Mac DT, et al. Improving alertness and performance in emergency department physicians and nurses: the use of planned naps. Ann Emerg Med. 2006;48:596-604, 604e1-604e3.

180. Sallinen M, Harma M, Akerstedt T, Rosa R, Lillqvist O. Promoting alertness with a short nap during a night shift. J Sleep Res. 1998;7: 240-247.

181. Purnell MT, Feyer AM, Herbison GP. The impact of a nap opportunity during the night shift on the performance and alertness of 12-h shift workers. J Sleep Res. 2002;11:219-227.

182. Nicholson AN, Pascoe PA, Roehrs T, et al. Sustained performance with short evening and morning sleeps. Aviat Space Environ Med. 1985;56:105-114.

183. Harma M, Knauth P, Ilmarinen J. Daytime napping and its effects on alertness and short-term memory performance in shiftworkers. Int Arch Occup Environ Health. 1989;61:341-345.

184. Sugerman JL, Walsh JK. Physiological sleep tendency and ability to maintain alertness at night. Sleep. 1989;12:106-112.

185. Signal TL, Gander PH, Anderson H, Brash S. Scheduled napping as a countermeasure to sleepiness in air traffic controllers. J Sleep Res. 2009;18:11-19.

186. Matsumoto K, Harada M. The effect of night-time naps on recovery from fatigue following night work. Ergonomics. 1994;37: 899-907.

187. Fallis WM, McMillan DE, Edwards MP. Napping during night shift: practices, preferences, and perceptions of critical care and emergency department nurses. Crit Care Nurse. 2011;31:e1-e11.

188. Scheer FA, Shea TJ, Hilton MF, Shea SA. An endogenous circadian rhythm in sleep inertia results in greatest cognitive impairment upon awakening during the biological night. J Biol Rhythms. 2008;23:353-361.

189. Silva EJ, Duffy JF. Sleep inertia varies with circadian phase and sleep stage in older adults. Behav Neurosci. 2008;122:928-935.

190. Badia P, Myers B, Boecker M, Culpepper J, Harsh JR. Bright light effects on body temperature, alertness, EEG and behavior. Physiol Behav. 1991;50:583-588.

191. Campbell SS, Dawson D. Enhancement of nighttime alertness and performance with bright ambient light. Physiol Behav. 1990;48:317-320.

192. Lavoie S, Paquet J, Selmaoui B, Rufiange M, Dumont M. Vigilance levels during and after bright light exposure in the first half of the night. Chronobiol Int. 2003;20:1019-1038.

193. Myers BL, Badia P. Immediate effects of different light intensities on body temperature and alertness. Physiol Behav. 1993;54:199-202.

194. Ruger M, Gordijn MCM, Beersma DGM, de Vries B, Daan S. Acute and phase-shifting effects of ocular and extraocular light in human circadian physiology. J Biol Rhythms. 2003;18:409-419.

195. Lowden A, Akerstedt T, Wibom R. Suppression of sleepiness and melatonin by bright light exposure during breaks in night work. J Sleep Res. 2004;13:37-43.

196. Ruger M, Gordijn MC, Beersma DG, de Vries B, Daan S. Time-of-daydependent effects of bright light exposure on human psychophysiology: comparison of daytime and nighttime exposure. Am J Physiol Regul Integr Comp Physiol. 2006;290:R1413-R1420.

197. Costa G, Gaffuri E, Ghirlanda G, Minors DS, Waterhouse JM. Psychophysical conditions and hormonal secretion in nurses on a rapidly rotating shift schedule and exposed to bright light during night work. Work Stress. 1995;9:148-157.

198. Costa G, Ghirlanda G, Minors D, Waterhouse JM. Effect of bright light on tolerance to night work. Scand J Work Environ Health. 1993;19:414-420.

199. Daurat A, Aguirre A, Foret J, Gonnet P, Keromes A, Benoit O. Bright light affects alertness and performance rhythms during a 24-h constant routine. Physiol Behav. 1993;53:929-936.

200. Cajochen C, Zeitzer JM, Czeisler CA, Dijk DJ. Dose-response relationship for light intensity and ocular and electroencephalographic correlates of human alertness. Behav Brain Res. 2000;115:75-83. 
201. Daurat A, Foret J, Benoit O, Mauco G. Bright light during nighttime: effects on the circadian regulation of alertness and performance. Biol Signals Recept. 2000;9:309-318.

202. Campbell SS, Dijk DJ, Boulos Z, Eastman CI, Lewy AJ, Terman M. Light treatment for sleep disorders: consensus report. III. Alerting and activating effects. J Biol Rhythms. 1995;10:129-132.

203. Cajochen C, Munch M, Kobialka S, et al. High sensitivity of human melatonin, alertness, thermoregulation, and heart rate to short wavelength light. J Clin Endocrinol Metab. 2005;90:1311-1316.

204. Lockley SW, Evans EE, Scheer FA, Brainard GC, Czeisler CA, Aeschbach D. Short-wavelength sensitivity for the direct effects of light on alertness, vigilance, and the waking electroencephalogram in humans. Sleep. 2006;29:161-168.

205. Revell VL, Arendt J, Fogg LF, Skene DJ. Alerting effects of light are sensitive to very short wavelengths. Neurosci Lett. 2006; 399:96-100.

206. Phipps-Nelson J, Redman JR, Dijk DJ, Rajaratnam SMW. Daytime exposure to bright light, as compared to dim light, decreases sleepiness and improves psychomotor vigilance performance. Sleep 2003;26:695-700.

207. Ruger M, Gordijn MC, Beersma DG, de Vries B, Daan S. Weak relationships between suppression of melatonin and suppression of sleepiness/fatigue in response to light exposure. J Sleep Res. 2005;14:221-227.

208. Bonnet MH, Arand DL. The use of prophylactic naps and caffeine to maintain performance during a continous operation. Ergonomics. 1994;37:1009-1020.

209. Eastman CI, Martin SK. How to use light and dark to produce circadian adaptation to night shift work. Ann Med. 1999;31:87-98.

210. Wever RA. The Circadian System of Man: Results of Experiments Under Temporal Isolation. Heidelberg: Springer-Verlag; 1979.

211. Aschoff J, Hoffmann K, Pohl H, Wever R. Re-entrainment of circadian rhythms after phase shifts of the zeitgeber. Chronobiologia. 1975;2:23-78.

212. Revell VL, Eastman CI. Jet lag and its prevention. In: Barkoukis TJ, Matheson JK, Ferber R, Doghramji K, editors. Therapy in Sleep Medicine. Philadelphia: Elsevier; 2012:390-401.

213. Revell VL, Eastman CI. How to trick Mother Nature into letting you fly around or stay up all night. J Biol Rhythms. 2005;20:353-365.

214. Eastman CI, Burgess HJ. How to travel the world without jet lag. Sleep Med Clin. 2009;4:241-255.

215. Eastman CI. Bright light in work-sleep schedules for shift workers: application of circadian rhythm principles. In: Rensing L, an der Heiden U, Mackey MC, editors. Temporal Disorder in Human Oscillatory Systems. Heidelberg: Springer-Verlag; 1987:176-185.

216. Eastman CI, Stewart KT, Mahoney MP, Liu L, Fogg LF. Dark goggles and bright light improve circadian rhythm adaptation to night-shift work. Sleep. 1994;17:535-543.

217. Mitchell PJ, Hoese EK, Liu L, Fogg LF, Eastman CI. Conflicting bright light exposure during night shifts impedes circadian adaptation. J Biol Rhythms. 1997;12:5-15.

218. Martin SK, Eastman CI. Medium-intensity light produces circadian rhythm adaptation to simulated night-shift work. Sleep. 1998;21:154-165.

219. Boivin DB, James FO. Circadian adaptation to night-shift work by judicious light and darkness exposure. J Biol Rhythms. 2002;17: $556-567$.

220. Lewy AJ, Sack RL. The dim light melatonin onset as a marker for circadian phase position. Chronobiol Int. 1989;6:93-102.

221. Benloucif S, Burgess HJ, Klerman EB, et al. Measuring melatonin in humans. J Clin Sleep Med. 2008;4:66-69.

222. Burgess HJ, Eastman CI. The dim light melatonin onset following fixed and free sleep schedules. J Sleep Res. 2005;14:229-237.

223. Cagnacci A, Soldani R, Laughlin GA, Yen SSC. Modification of circadian body temperature rhythm during the luteal menstrual phase: role of melatonin. J Appl Physiol. 1996;80:25-29.
224. Goel N. Late-night presentation of an auditory stimulus phase delays human circadian rhythms. Am J Physiol Regul Integr Comp Physiol. 2005;289:R209-R216.

225. Goel N. An arousing, musically enhanced bird song stimulus mediates circadian rhythm phase advances in dim light. Am J Physiol Regul Integr Comp Physiol. 2006;291:R822-R827.

226. Eastman CI, Martin SK, Hebert M. Failure of extraocular light to facilitate circadian rhythm reentrainment in humans. Chronobiol Int. 2000;17:807-826.

227. Mongrain V, Lavoie S, Selmaoui B, Paquet J, Dumont M. Phase relationships between sleep-wake cycle and underlying circadian rhythms in morningness-eveningness. J Biol Rhythms. 2004;19:248-257.

228. Griefahn B. The validity of the temporal parameters of the daily rhythm of melatonin levels as an indicator of morningness. Chronobiol Int. 2002;19:561-577.

229. Benloucif S, Guico MJ, Reid KJ, Wolfe LF, L'Hermite-Baleriaux M, Zee PC. Stability of melatonin and temperature as circadian phase markers and their relation to sleep times in humans. J Biol Rhythms. 2005;20:178-188.

230. Griefahn B, Kunemund C, Golka K, Thier R, Degen G. Melatonin synthesis: a possible indicator of intolerance to shiftwork. Am J Ind Med. 2002;42:427-436.

231. Burgess HJ, Revell VL, Molina TA, Eastman CI. Human phase response curves to three days of daily melatonin: $0.5 \mathrm{mg}$ versus $3.0 \mathrm{mg}$. J Clin Endocrinol Metab. 2010;95:3325-3331.

232. Sharkey KM, Eastman CI. Melatonin phase shifts human circadian rhythms in a placebo-controlled simulated night-work study. Am J Physiol. 2002;282:R454-R463.

233. Sack RL, Lewy AJ. Melatonin as a chronobiotic: treatment of circadian desynchrony in night workers and the blind. J Biol Rhythms. 1997;12:595-603.

234. Crowley SJ, Lee C, Tseng CY, Fogg LF, Eastman CI. Combinations of bright light, scheduled dark, sunglasses, and melatonin to facilitate circadian entrainment to night shift work. J Biol Rhythms. 2003; 18:513-523.

235. Baehr EK, Fogg LF, Eastman CI. Intermittent bright light and exercise to entrain human circadian rhythms to night work. Am J Physiol. 1999;277:R1598-R1604.

236. Rimmer DW, Boivin DB, Shanahan TL, Kronauer RE, Duffy JF, Czeisler CA. Dynamic resetting of the human circadian pacemaker by intermittent bright light. Am J Physiol. 2000;279:R1574-R1579.

237. Gronfier C, Wright KP, Kronauer RE, Jewett ME, Czeisler CA. Efficacy of a single sequence of intermittent bright light pulses for delaying circadian phase in humans. Am J Physiol. 2004;287:E174-E181.

238. Burgess HJ, Crowley SJ, Gazda CJ, Fogg LF, Eastman CI. Preflight adjustment to eastward travel: 3 days of advancing sleep with and without morning bright light. J Biol Rhythms. 2003;18:318-328.

239. Crowley SJ, Lee C, Tseng CY, Fogg LF, Eastman CI. Complete or partial circadian re-entrainment improves performance, alertness, and mood during night shift work. Sleep. 2004;27:1077-1087.

240. Lee C, Smith M, Eastman C. A compromise phase position for permanent night shift workers: circadian phase after two night shifts with scheduled sleep and light/dark exposure. Chronobiol Int. 2006;23:859-875.

241. Smith MR, Cullnan EE, Eastman CI. Shaping the light/dark pattern for circadian adaptation to night shift work. Physiol Behav. 2008;95:449-456.

242. Smith MR, Eastman CI. Night shift performance is improved by a compromise circadian phase position: study 3 . Circadian phase after 7 night shifts with an intervening weekend off. Sleep. 2008;31:1639-1645.

243. Smith MR, Fogg LF, Eastman CI. Practical interventions to promote circadian adaptation to permanent night shift work: study 4. J Biol Rhythms. 2009;24:161-172.

244. Smith MR, Fogg LF, Eastman CI. A compromise circadian phase position for permanent night work improves mood, fatigue, and performance. Sleep. 2009;32:1481-1489. 
245. Brainard GC, Hanifin JP, Greeson JM, et al. Action spectrum for melatonin regulation in humans: evidence for a novel circadian photoreceptor. J Neurosci. 2001;21:6405-6412.

246. Thapan K, Arendt J, Skene DJ. An action spectrum for melatonin suppression: evidence for a novel non-rod, non-cone photoreceptor system in humans. J Physiol. 2001;535:261-267.

247. Lockley SW, Brainard GC, Czeisler CA. High sensitivity of the human circadian melatonin rhythm to resetting by short wavelength light. J Clin Endocrinol Metab. 2003;88:4502-4505.

248. Warman VL, Dijk DJ, Warman GR, Arendt J, Skene DJ. Phase advancing human circadian rhythms with short wavelength light. Neurosci Lett. 2003;342:37-40.

249. Smith M, Revell V, Lee C, Eastman C. Bright blue-enriched light did not produce larger phase delays than bright white light. Soc Light Treatment Biol Rhythms Abstr. 2006;18:30.

250. Dinges DF, Powell JW. Microcomputer analyses of performance on a portable, simple visual RT task during sustained operations. Behav Res Methods Instrum Comput. 1985;17:652-655.

251. Dijk DJ, Duffy JF, Riel E, Shanahan TL, Czeisler CA. Ageing and the circadian and homeostatic regulation of human sleep during forced desynchrony of rest, melatonin and temperature rhythms. J Physiol. 1999;516:611-627.

252. Eastman CI. How to get a bigger dose of bright light. Sleep. 2011; 34:559-560.

253. Smith MR, Revell VL, Eastman CI. Phase advancing the human circadian clock with blue-enriched polychromatic light. Sleep Med. 2009;10:287-294.

254. Smith MR, Eastman CI. Phase delaying the human circadian clock with blue-enriched polychromatic light. Chronobiol Int. 2009;26:709-725.
255. Revell VL, Burgess HJ, Gazda CJ, Smith MR, Fogg LF, Eastman CI. Advancing human circadian rhythms with afternoon melatonin and morning intermittent bright light. J Clin Endocrinol Metab. 2006;91:54-59.

256. Revell VL, Molina TA, Eastman CI. Human phase response curve to intermittent blue light using a commercially available device. JPhysiol. Epub July 2, 2012.

257. Paul MA, Miller JC, Gray G, Buick F, Blazeski S, Arendt J. Circadian phase delay induced by phototherapeutic devices. Aviat Space Environ Med. 2007;78:645-652.

258. Gamble KL, Motsinger-Reif AA, Hida A, et al. Shift work in nurses: contribution of phenotypes and genotypes to adaptation. PLoS One. 2011;6:e18395.

259. Gumenyuk V, Roth T, Drake CL. Circadian phase, sleepiness, and light exposure assessment in night workers with and without shift work disorder. Chronobiol Int. 2012;29:928-936.

260. Burke T, Markwald R, McHill A, et al. Evening caffeine phase delays the human circadian clock. Sleep. 2012;35:A205.

261. Wittmann M, Dinich J, Merrow M, Roenneberg T. Social jetlag: misalignment of biological and social time. Chronobiol Int. 2006;23:497-509.

262. Crowley SJ, Acebo C, Carskadon MA. Sleep, circadian rhythms, and delayed phase in adolescence. Sleep Med. 2007;8:602-612.

263. National Sleep Foundation. 2006 Sleep in America Poll: Teens and Sleep. Available from: http://www.sleepfoundation.org. Accessed August 20, 2012.

264. Eastman CI. Circadian rhythms and bright light: recommendations for shift work. Work Stress. 1990;4:245-260.
Nature and Science of Sleep

\section{Publish your work in this journal}

Nature and Science of Sleep is an international, peer-reviewed, open access journal covering all aspects of sleep science and sleep medicine, including the neurophysiology and functions of sleep, the genetics of sleep, sleep and society, biological rhythms, dreaming, sleep disorders and therapy, and strategies to optimize healthy sleep. The journal welcomes

\section{Dovepress}

original research, clinical \& epidemiological studies, reviews \& evaluations, case reports and extended reports. The manuscript management system is completely online and includes a very quick and fair peerreview system, which is all easy to use. Visit http://www.dovepress.com/ testimonials.php to read real quotes from published authors. 